\title{
THERMAL NEUTRON DIFFUSION IN LIGHT AND HEAVY WATER
}

\author{
P. B. PARKS \\ D. J. PELLARIN
}

N. H. PROCHNOW

N. P. BAUMANN
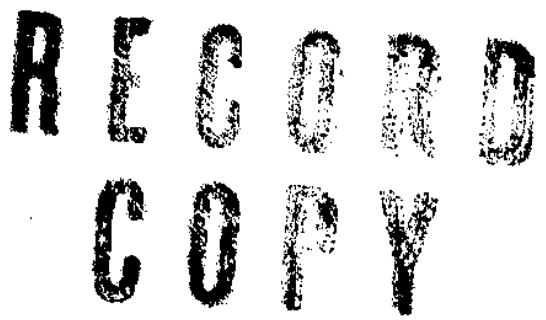

DO NOI RE

FROA

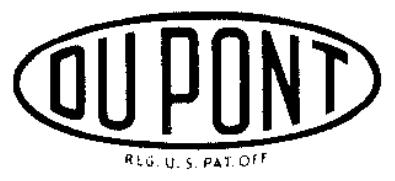

Savannah River Laboratory

Aiken, South Carolina 


\section{LEGAL NOTICE}

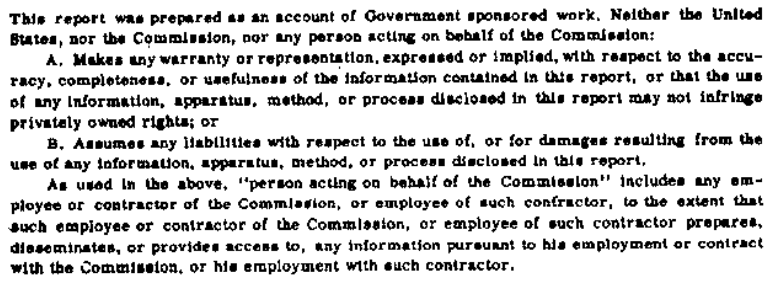

Printed in the United States of America

Available from

Clearinghouse for Federal Scientific and Technical Information National Bureau of Standards, U. S. Department of Commerce Springfield, Virginia 22151

Price: Printed Copy $\$ 3.00$; Microfiche $\$ 0.65$ 


\title{
THERMAL NEUTRON DIFFUSION IN LIGHT AND HEAVY WATER
}

\author{
by \\ P. B. Parks \\ D. J. Pellarin \\ N. H. Prochnow* \\ N. P. Baumann \\ Approved by \\ B. C. Rusclie, Research Manager \\ Experimental Physics Division \\ February 1968

\begin{abstract}
*Present address: Wisconsin State University, River Falls, Wisconsin
\end{abstract} \\ E. I. DU PONT DE NEMOURS \& COMPANY \\ SAVANNAH RIVER LABORATORY \\ AIKEN, S. C. 29801 \\ CONTRACT AT(07.2)-1 WITH THE \\ UNITED STATES ATOMIC ENERCY COMMISSION
}




\section{ABSTRACT}

The thermal neutron diffusion coefficients for $\mathrm{H}_{2} \mathrm{O}$ and $\mathrm{D}_{2} \mathrm{O}$ were determined from static measurements of the neutron relaxation length in boron-poisoned $\mathrm{H}_{2} \mathrm{O}$ and $\mathrm{D}_{2} \mathrm{O}$ and pulsed measurements of the neutron die-away in different-sized containers of these two moderators. The $\mathrm{H}_{2} \mathrm{O}$ results agree well with previous measurements and fairly well with theory. The diffusion coefficients determined for $\mathrm{H}_{2} \mathrm{O}$ are:

$$
\begin{aligned}
& D_{O}=3.57 \pm 0.04 \times 10^{4} \mathrm{~cm}^{2} \mathrm{sec}^{-1} \\
& C=3.31 \pm 0.15 \times 10^{3} \mathrm{~cm}^{4} \mathrm{sec}^{-1} \\
& F=2.8 \pm 0.7 \times 10^{2} \mathrm{~cm}^{6} \mathrm{sec}^{-1}
\end{aligned}
$$

The $\mathrm{D}_{2} \mathrm{O}$ results agree reasonably well with calculations in the range of poison concentrations $\Sigma_{a}(B)=-0.04$ to $+0.04 \mathrm{~cm}^{-1}$. The restricted diffusion coefficients determined for $\mathrm{D}_{2} \mathrm{O}$ are:

$$
\begin{aligned}
& D_{O}=2.09 \pm 0.02 \times 10^{5} \mathrm{~cm}^{2} \mathrm{sec}^{-1} \\
& C=6.6 \pm 0.03 \times 10^{5} \mathrm{~cm}^{4} \mathrm{sec}^{-1}
\end{aligned}
$$

The pulsed measurements for $\mathrm{D}_{2} \mathrm{O}$ resolved a previous discrepancy between pulsed and static determinations of $\mathrm{D}_{0}$. The static measurements included neutron spectral index determinations as a function of neutron source and poisoning conditions. The theoretically predicted strong dependence of spectral indices on neutron source conditions in $\mathrm{D}_{2} \mathrm{O}$ was verified. Evidence was also found for the existence of a pseudo energy equilibrium distribution in heaviiy poisoned $\mathrm{D}_{2} \mathrm{O}$. Normal analysis of this unusual data led to an assignment of the inverse diffusion length, $k$, which exceeded Corngold's limit at $k=\Sigma_{s}$, the free atom scattering cross section. 


\section{CONTENTS}

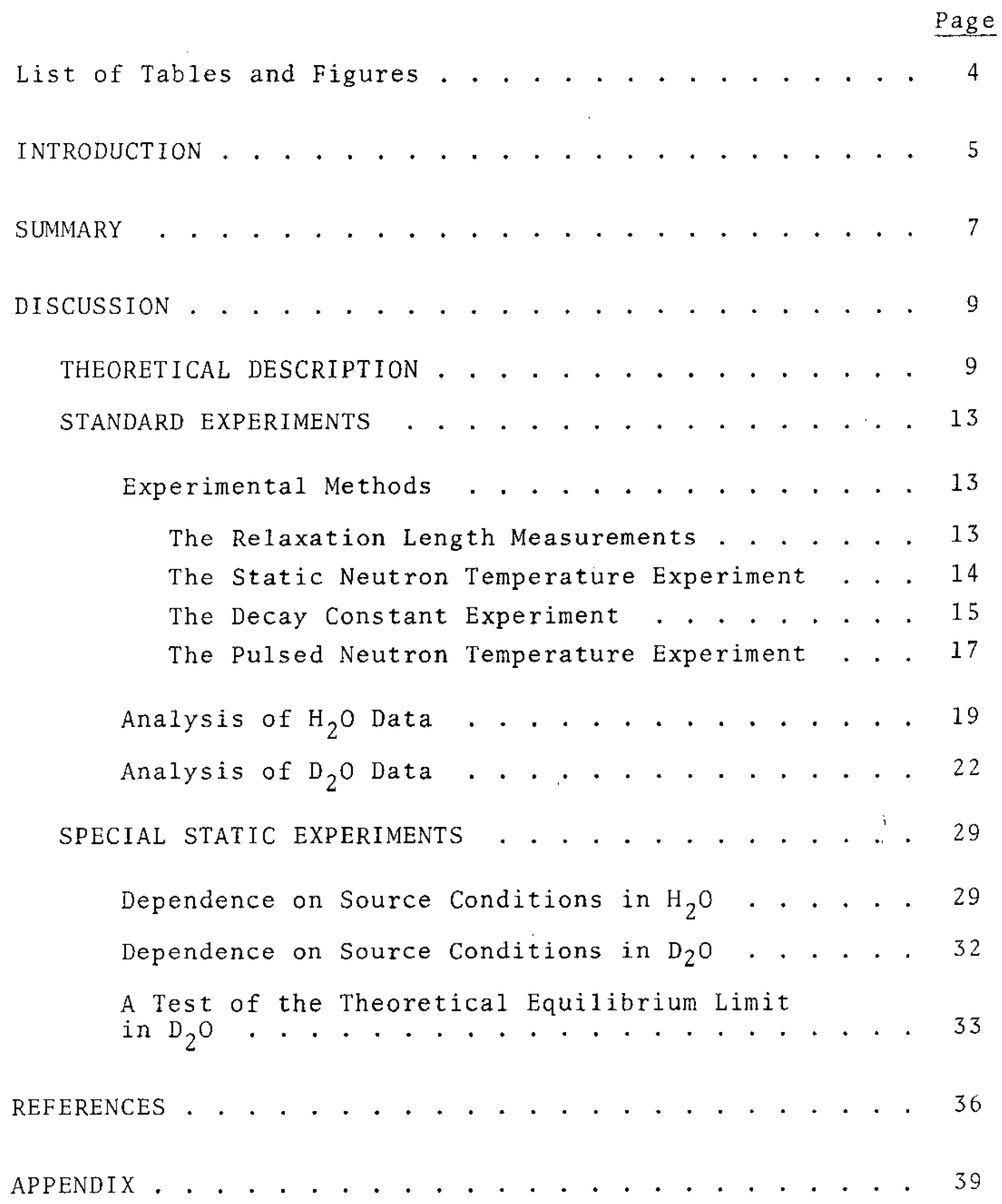




\section{LIST OF TABLES AND FIGURES}

Table

$\underline{\text { Page }}$

I Dimensions of Aluminum Cylinders Used for Pulsed Measurements... . . . . . . . . . . . 16

I Static and Pulsed Measurements in $\mathrm{H}_{2} \mathrm{O}$. . . . . . . 20

II Inverse Diffusion Lengths and Neutron Temperatures

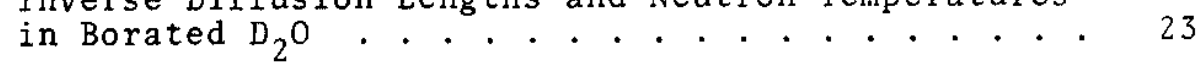

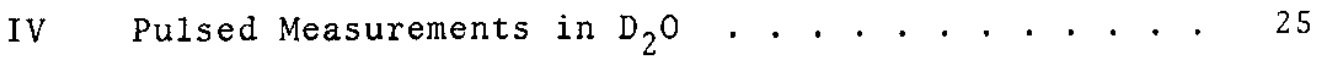

V Special Static Experiments . . . . . . . . . . . . 31

Figure

1 Source Reactor and Exponential Facility . . . . . . 13

2 Neutron Generator, Sample, and Shield Box . . . . 15

3 Pulsed Neutron Temperature Experiment . . . . . . . 18

4 Comparison of Experimental Data to Theoretical Calculations for $\mathrm{H}_{2} \mathrm{O}$. . . . . . . . . . . . . . . . 21

5 Approach to Equilibrium in Relaxation Length Measurements on Borated $\mathrm{D}_{2} \mathrm{O} \cdot$. . . . . . . . . . 24

6 Comparison of Experimental Data to Theoretical Calculations for $\mathrm{D}_{2} \mathrm{O} \cdot$. . . . . . . . . . . . . 26

7 Restricted Range Experimental Data in $\mathrm{D}_{2} \mathrm{O} \cdot$. $\cdot$. $\quad 28$

8 Comparison of Asymptotic Neutron Temperatures Derived from Spectral Index Measurements and

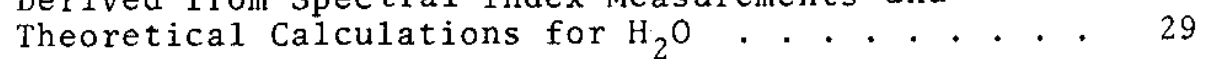

9 Comparison of Asymptotic Neutron Temperatures Derived from Spectral Index Measurements and

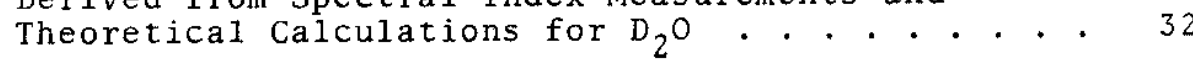

10 Neutron Temperatures Derived from Spectral Index Measurements in Heavily Poisoned $D_{2} \mathrm{O}$ Versus

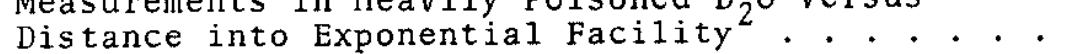




\section{INTRODUCTION}

Neutron relaxation lengths in poisoned moderating media and pulsed neutron decay constants in unpoisoned media are often measured to determine thermal neutron diffusion coefficients. However, these measurements can be misinterpreted because of improper treatment of angular distribution effects and variations in the neutron energy spectrum. The angular effects can be easily corrected by straightforward transport theory calculations, but the equilibrium spectra depend on the complex mechanisms of both the energy transfer to and from the moderating atoms (Scattering Kernel) and the nature of the static source feed.

In earlier Savannah River Laboratory (SRL) measurements ${ }^{1}$ of the relaxation length of thermal neutrons in lightly poisoned $\mathrm{D}_{2} \mathrm{O}$, corrections were made for the poison-induced shifts in the energy spectrum as well as for the transport effects. However, the spectral correction used Westcott!'s relation derived for the high-energy source feed normally found in multiplying systems. Honeck and Michae ${ }^{2}$ have pointed out that, for the thermal source actually used, the use of Westcott's relation leads to too large a correction. The resulting error in the reported SRL measurements was, nevertheless, within the quoted errors. Experiments have been designed to verify the extent to which source conditions affect the interpretation of the measurements.

Honeck ${ }^{3}$ has treated the relationship of the effective diffusion coefficient and poison concentration by integral transport calculations in which he assumed a thermal feed; but, for the SRL measurements, the added poison was so small that Honeck's derived $\mathrm{D}_{2} \mathrm{O}$ coefficients could not be verified on the basis of the SRL data alone. Existing pulsed measurements ${ }^{4,5}$, on $\mathrm{D}_{2} \mathrm{O}$ did appear to support Honeck's calculation of the energy shift (as represented by the cooling coefficient, C) but were questionable because the pulsed diffusion coefficient for zero spectral shift, $D_{0}$, disagreed with that derived from static measurements. The average pulsed diffusion coefficient, $D_{0}$, was $2.00 \pm 0.01 \times 10^{5} \mathrm{~cm}^{2} \mathrm{sec}^{-1}$ for pure $\mathrm{D}_{2} \mathrm{O}$ at $20^{\circ} \mathrm{C}$ compared to an average $\mathrm{D}_{0}$ of $2.10 \pm 0.02 \times 10^{5} \mathrm{cml}^{2} \mathrm{sec}^{-1}$ 
for the static measurements. New pulsed and static measurements in $\mathrm{H}_{2} \mathrm{O}$, as well as in $\mathrm{D}_{2} \mathrm{O}$, have been designed which can be used to test Honeck's calculations.

Deep-poisoned experiments have recently become of interest as a result of theoretical discussions on the limits for which the Boltzmann diffusion equation is formally solvable and on the interpretation of measurements made beyond these limits (Corngold ${ }^{7}$ ). In the $\mathrm{D}_{2} \mathrm{O}$ static experiment a test of one of the formal limits has been accomplished by adding sufficient poison so that $k$, the inverse diffusion length, approaches $\Sigma_{s}$, the free atom scattering cross section. 


\section{SUMMARY}

Pulsed and static experiments were made in $\mathrm{H}_{2} \mathrm{O}$ and $\mathrm{D}_{2} \mathrm{O}$ to determine diffusion coefficients for these moderators. The experiments included separate investigations of the effects of diffusion cooling, absorption hardening induced by boron poisoning, and neutron source conditions: Spectral indices were measured, in addition to the normal relaxation length and time decay, to determine the magnitude of neutron spectral shifts. The experiments were accompanied by a parallel computational program utilizing Monte Car $10^{8}$ calculations and integral transport calculations by THERMOS. ${ }^{9}$

The SRL $\mathrm{H}_{2} \mathrm{O}$ measurements agreed well with the static measurements of Starr and Koppe $1^{20}$ and with the pulsed measurements of Gon et al. ${ }^{11}$ Therefore these three sets of measurements were standardized to $\sigma_{B}=759$ barns, $\sigma_{H}=0.332$ barns, $^{12}$ and moderator temperature $=20^{\circ} \mathrm{C}$. The results of a least squares parametric fit (excepting only the SRL spectral index data) are:

$$
\begin{aligned}
& D_{0}=3.57 \pm 0.04 \times 10^{4} \mathrm{~cm}^{2} \mathrm{sec}^{-1} \\
& C=3.31 \pm 0.15 \times 10^{3} \mathrm{~cm}^{4} \mathrm{sec}^{-1} \\
& F=2.8 \pm 0.7 \times 10^{2} \mathrm{~cm}^{6} \mathrm{sec}^{-1}
\end{aligned}
$$

These values compare with Honeck's ${ }^{3}$ calculations of $D_{0}=3.753 \mathrm{x}$ $10^{4} \mathrm{~cm}^{2} \mathrm{sec}^{-1}, \mathrm{C}=3.130 \times 10^{3} \mathrm{~cm}^{4} \mathrm{sec}^{-1}$, and $\mathrm{F}=2.700 \times 10^{2}$ $\mathrm{cm}^{6} \mathrm{sec}^{-1}$. Spectral index data could not be converted to values comparable to the normal relaxation length measurements because of poor convergence in the $\mathrm{P}_{\mathrm{n}}$ theoretical treatment. However, measured and predicted spectral indices in $\mathrm{H}_{2} \mathrm{O}$ agreed well.

In $\mathrm{D}_{2} \mathrm{O}$, the $\mathrm{SRL}$ pulsed and static measurements agreed with each other and agreed with Honeck's calculations over a limited range of buckling and poisoning values corresponding to an effective $\Sigma_{a}$ between -0.04 and $+0.04 \mathrm{~cm}^{-1}$. The experimental diffusion coefficients corrected to $20^{\circ} \mathrm{C}$ and $100 \mathrm{~mol} \div \mathrm{D}_{2} \mathrm{O}$ were: 


$$
\begin{aligned}
D_{0} & =2.09 \pm 0.02 \times 10^{5} \mathrm{~cm}^{2} \mathrm{sec}^{-1} \\
C & =6.6 \pm 0.3 \times 10^{5} \mathrm{~cm}^{4} \mathrm{sec}^{-1}
\end{aligned}
$$

These experimental numbers compare with Honeck's ${ }^{3}$ calculations of $D_{0}=2.072 \times 10^{5} \mathrm{~cm}^{2} \mathrm{sec}^{-1}$ and $\mathrm{C}=5.129 \times 10^{5} \mathrm{~cm}^{4} \mathrm{sec}^{-1}$.

Our $\mathrm{D}_{2} \mathrm{O}$ measurements confirmed Honeck and Michael's results, which showed that the energy spectral shift due to the boron addition should depend on whether a thermal or epithermal neutron source feeds the assembly. We also showed that by properly tailoring the neutron source, a pseudo equilibrium condition could be obtained in heavily poisoned $\mathrm{D}_{2} \mathrm{O}$ such that the experimentally assigned value of $k$ exceeded the theoretical limit of $\Sigma_{S}($ free atom). 


\section{DISCUSSION}

\section{THEORETICAL DESCRIPTION}

The theoretical behavior of the steady-state flux from a distributed neutron source in a diffusing medium has been adequately described. ${ }^{3}$ If a source is placed at one end of a sample and if one neglects energy nonequilibrium, the thermal neutron flux is given by an infinite sum of spatial harmonics. For example, if the source is placed on the xy plane at one end of a rectangular parallelopiped with extrapolated dimensions $a, b$, and $c$, the neutron flux is given by

$$
\phi(x, y, z)=\sum_{m} \sum_{n} A_{m n} \sin \left(\frac{m \pi x}{a}\right) \sin \left(\frac{n \pi y}{b}\right) \sinh \left[\gamma_{m n}(c-z)\right]
$$

where the A $A_{m n}$ 's are harmonic amplitude coefficients. The harmonic relaxation lengths $\gamma_{m n}$ are given by

$$
\gamma_{m n}^{2}=k^{2}+\left(\frac{m \pi}{a}\right)^{2}+\left(\frac{n \pi}{b}\right)^{2} \equiv k^{2}+B_{m n}^{2}(a, b)
$$

where

$$
\kappa^{2}=\frac{\Sigma_{a}}{D}
$$

the macroscopic absorption cross section divided by the diffusion coefficient.

The thermal-neutron population of a pulsed medium as a function of time is given by a similar sum. For instance in a cylinder of extrapolated radius $R$ and height $H$,

$$
\phi(r, \theta, z, t)=\sum_{\ell} \sum_{m} \sum_{n} A_{\ell m n} J_{m}\left(\frac{a_{m \ell^{r}}}{R}\right) \cos (m \theta) \sin \left(\frac{n \pi z}{H}\right) e^{-\lambda \ell m n}{ }^{t}
$$

where $J_{m}\left(\frac{a_{m \ell^{r}}}{R}\right)$ is a Bessel function of the first kind, $a_{m \ell}$ is 
one of the roots of that function, and $\lambda_{\ell m n}$ is the harmonic decay constant of the material.

In both static and pulsed experiments, the fundamental mode $(\ell=m=n=1)$ is the most persistent, and in principle can be isolated at large $z$ or $t$ values. Honeck has shown the relationship between the fundamental modes in these two experiments. ${ }^{3}$ The reciprocal of the diffusion length, $k$, in a poisoned moderator at absolute temperature $T_{0}$ is usually expressed as a function of the poison concentration by the polynomial expansion,

$$
k^{2}=\alpha_{1} \Sigma_{a}\left(k T_{0}\right)-\alpha_{2} \Sigma_{a}^{2}\left(k T_{0}\right)+\alpha_{3} \Sigma_{a}^{3}\left(k T_{0}\right)+\ldots
$$

where $k$ is Boltzmann's constant. Similarly, the fundamental mode decay constant of a pulsed sample is given by the buckling expansion,

$$
\lambda=\overline{v \Sigma_{2}}+D_{o} B^{2}-C B^{4}+F B^{6}+\ldots \equiv \overline{v \Sigma_{a}}+\left(v D_{e f f}\right) B^{2}
$$

where $\overline{v \Sigma_{a}}$ is usually written as $\lambda_{0}$ for $1 / v$ absorbers.

The identical neutron balance equation describes both experiments in Honeck's time separable treatment when the following identifications are made:

$$
\begin{gathered}
\kappa^{2} \rightarrow-B^{2} \\
\Sigma_{a}\left(k T_{0}\right) \rightarrow \frac{\lambda-\lambda_{0}}{v\left(k T_{0}\right)}
\end{gathered}
$$

The expansion coefficients of the static experiment are then related to the better known pulsed parameters by the equations,

$$
\mathrm{D}_{0}=\frac{\mathrm{v}\left(\mathrm{kT} \mathrm{T}_{0}\right)}{\alpha_{1}}
$$




$$
\begin{aligned}
& \mathrm{C}=\frac{\mathrm{v}\left(\mathrm{kT_{0 }}\right) \alpha_{2}}{\alpha_{1}^{3}} \\
& F=\frac{v\left(k T_{0}\right)\left(2 \alpha_{2}^{2}-\alpha_{1} \alpha_{3}\right)}{\alpha_{1}^{5}}
\end{aligned}
$$

The coefficients of Equation 3 may be determined experimentally by measuring $k$ at several known poison concentrations. Similarly the coefficients of Equation 4 may be determined by measuring the decay constant at several known bucklings.

By noting that only the angular distribution and the neutron temperature effects change $\mathrm{D}_{\text {eff }}$ when the poison concentration or the sample dimensions are varied, one may then write for a moderator at temperature $\mathrm{T}_{0}$ and neutron temperature $\mathrm{T}_{\mathrm{n}}$;

$$
D_{\text {eff }}=D\left(T_{0}\right)\left[A+(1-A)\left(\frac{T_{n}}{T_{0}}\right)^{\frac{1}{2}}\right](1+\delta)
$$

where it is assumed that the angular distribution and neutron temperature effects are independent. The expression in square brackets is a semiempirical expression ${ }^{1}$ for the dependence of $\mathrm{D}$ on $\mathrm{T}_{\mathrm{n}}$; at $\mathrm{T}_{0}=293^{\circ} \mathrm{K}, \mathrm{A}=0.69$ for $\mathrm{D}_{2} \mathrm{O}$ and 0.06 for $\mathrm{H}_{2} \mathrm{O}$. The quantity $\delta$ is the angular distribution correction which in the $\mathrm{P}_{3}$ approximation to monoenergetic transport theory is given closely by

$$
\begin{aligned}
& \delta\left(\mathrm{P}_{3}\right)=\left[\Sigma_{\mathrm{a}} /\left(\begin{array}{ll}
5 & \left.\Sigma_{\mathrm{Tr}}\right)
\end{array}\right]\left(1+4 \bar{\mu}_{0}\right) \quad\right. \text { Static } \\
& \delta\left(\mathrm{P}_{3}\right)=\left[\mathrm{B}^{2} /\left(\begin{array}{ll}
15 & \Sigma_{\mathrm{Tr}}^{2}
\end{array}\right)\right]\left(1+4 \bar{\mu}_{0}\right) \quad \text { Pulsed }
\end{aligned}
$$

where $\bar{\mu}_{0}$ is the average cosine of the scattering angle. 
Equation 9 was derived explicitly for pulsed systems by Sjostrand. ${ }^{4}$ It also follows directly from the application of the equivalence relations of Equation 5 to the well known static relation, Equation 8 . The Maxwellian average values of $\bar{\mu}_{0}$ for $\mathrm{H}_{2} \mathrm{O}$ and $\mathrm{D}_{2} \mathrm{O}$ have been evaluated by Radkowsky's method ${ }^{15}$ in earlier work. ${ }^{1}$ At $20^{\circ} \mathrm{C}, \vec{\mu}_{0}$ is 0.32 for $\mathrm{H}_{2} \mathrm{O}$ and 0.14 for $\mathrm{D}_{2} \mathrm{O}$.

Except for $\delta$, which may readily be evaluated from Equations 8 or $9, D_{\text {eff }}$, as given by Equation 7 , depends only on $T_{n}$ for a given $T_{0}$. Therefore, since the dependence of $\Sigma_{a}$ on $T_{n}$ is trivial, a measurement of $\mathrm{T}_{n}$ alone will give the variation of $\kappa^{2}$ with $\Sigma_{a}$ by the relation

$$
\kappa^{2}=\left(\Sigma_{a}\right) \text { eff } / D_{\text {eff }}
$$

To obtain absolute values of $\mathrm{D}_{\text {eff }}$ from Equation $7, \mathrm{D}\left(\mathrm{T}_{0}\right)$ must be independently determined. 


\section{STANDARD EXPERIMENTS}

\section{Experimental Methods}

The Relaxation Length Measurements

Relaxation length measurements were made in a cadmium-1ined Side Tank, a 2-foot cube positioned adjacent to and centered on a 5-foot-square face of the Standard Pile (SP) ${ }^{16}$ (Figure 1). A $\mathrm{D}_{2} \mathrm{O}$-filled Slab Tank, 4 inches thick, was interposed between the Side Tank and the SP to increase the thermal-to-epithermal flux ratio in the side Tank. The neutron flux distribution in the Side Tank was measured by activating bare gold pins, $1 / 2$ inch long and $1 / 16$ inch in diameter, which were placed in holes drilled in a thin-walled aluminum tube extending through the tank. The distance between adjacent pins was either 0.250 or 0.500 inch. Activations due to epithermal source neutrons were subtracted by standard cadmium shutter techniques.

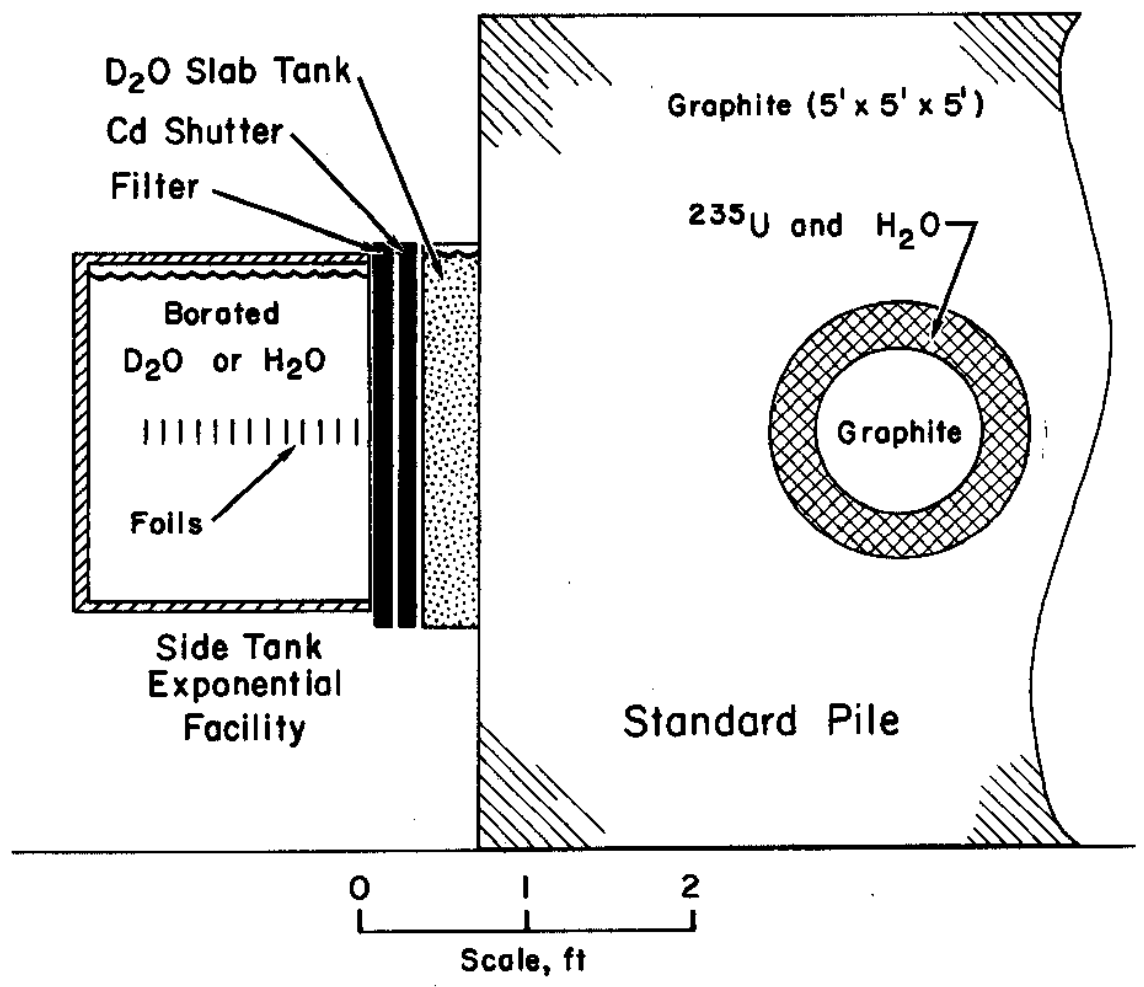

FIG. I SOURCE REACTOR AND EXPONENTIAL FACILITY 
$\mathrm{B}_{2} \mathrm{O}_{3}$ was the neutron poison. For $\mathrm{H}_{2} \mathrm{O}$, the highest poison concentration was used first and then diluted successively for lower concentrations. For $\mathrm{D}_{2} \mathrm{O}$, anhydrous $\mathrm{B}_{2} \mathrm{O}_{3}$ was added in known increments to a fixed amount of $\mathrm{D}_{2} \mathrm{O}$. The absolute boron content of the stock material was determined by mannitol titration and by total dehydration of representative samples in a vacuum oven. The boron isotopic ratio was determined by mass spectrometry. The $\mathrm{D}_{2} \mathrm{O}$ purity decreased from 99.84 to 99.78 mol $\%$ during the experiment. The added light water from the nominally anhydrous $\mathrm{B}_{2}{ }^{0} 3$ accounts for 0.026 mol $\%$ of this decrease.

\section{The Static Neutron Temperature Experiment}

The neutron temperature indices were measured from $\Sigma_{\mathrm{a}}(B)=$ 0 to $0.38 \mathrm{~cm}^{-1}$ in the poisoned $\mathrm{H}_{2} \mathrm{O}$, and from $\Sigma_{a}(B)=0$ to $0.06 \mathrm{~cm}^{-1}$ in the poisoned $\mathrm{D}_{2} \mathrm{O}$. $\mathrm{Lu}_{2} \mathrm{O}_{3}$ foils $(1 / 2$-inch diameter $x 0.020$ inch thick, 20 wt: $\mathrm{Lu}_{2}{ }^{0} 3$ in aluminum matrix) were used as spectral index detectors. In some cases, the lutetium foils were combined with 0.005 -inch-thick copper foils into composite foils. The spectral index determination ${ }^{17}$ involved the simultaneous irradiation of reference lutetium (and copper) foils in the graphite thermal column of the SP ( $1 / \mathrm{v}$ cadmium ratio $>10^{4}$ ) for each sample foil irradiated in the Side Tank. By comparing the ratio of the thermal ${ }^{177} \mathrm{Lu}$ to ${ }^{176} \mathrm{Lu}$ (or ${ }^{64} \mathrm{Cu}$ ) activities ratio at the reference to that at test positions, the neutron temperature, $T_{n}$, at the sample position was inferred. This temperature was normalized to the moderator temperature, $\mathrm{T}_{0}$, at the reference position in the graphite, where it was assumed that the thermal neutrons were in temperature equilibrium with the graphite. The light poison experiments were designed to obtain spectral indices for a purely thermal neutron source feeding in from the outside. Since, the available neutron source contained both a thermal and an epithermal component, a cadmium shutter was used to eliminate the effect of epithermal neutrons.

The use of the two lutetium isotopes in single foils was preferred over the combined foils because of the advantage of having identical positions for the two isotopes in the 
high-flux gradients. The usual objection to ${ }^{175}$ Lu as a target atom (a high background due to its high resonance integral) did not apply to most cases because the fluxes were highly thermalized at the foil positions.

\section{The Decay Constant Experiment}

The neutron source was a Texas Nuclear double-pulsed, $150 \mathrm{kv}$ accelerator in which deuterons bombard a target containing tritium (Figure 2). Thin-wall aluminum cylinders of the dimensions listed in Table I contained samples of $99.84 \operatorname{mol} \div \mathrm{D}_{2} \mathrm{O}$ or deionized $\mathrm{H}_{2} \mathrm{O}$; the sample heights were known within $\pm 0.02 \mathrm{~cm}$. In the two largest cylinders, cadmium sheets were inserted on the underside of the cover plate to eliminate backscattering from the plate; ${ }^{1 \theta}$ however, no discernible difference was observed without the cadmium. Targets were placed on the vertical axis of the samples with 6 inches of bottom clearance. $D_{2} O$ was transferred by dried helium gas under pressure. The helium also minimized isotopic degradation.

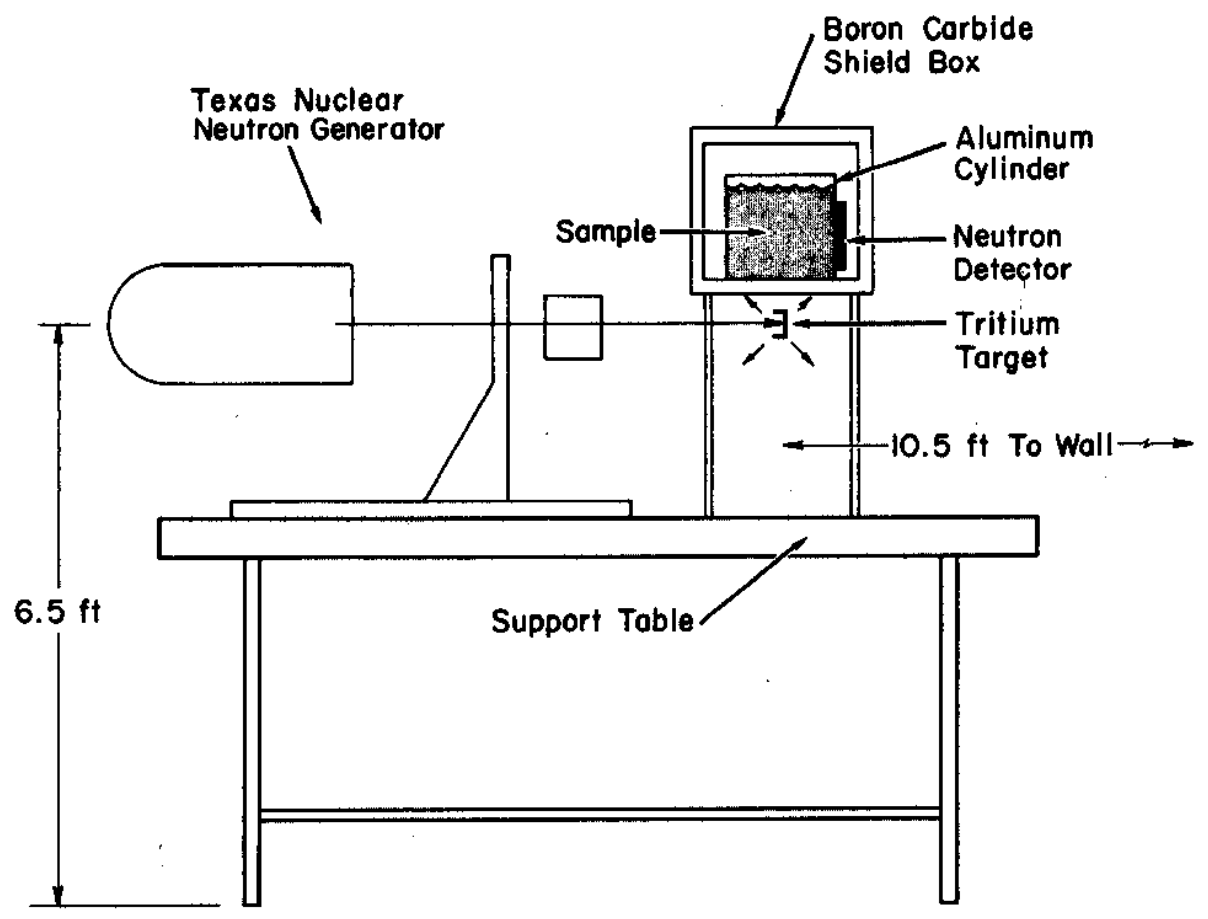

FIG. 2 NEUTRON GENERATOR, SAMPLE, AND SHIELD BOX 
TABLE I

Dimensions of Aluminum Cylinders Used for Pulsed Measurements

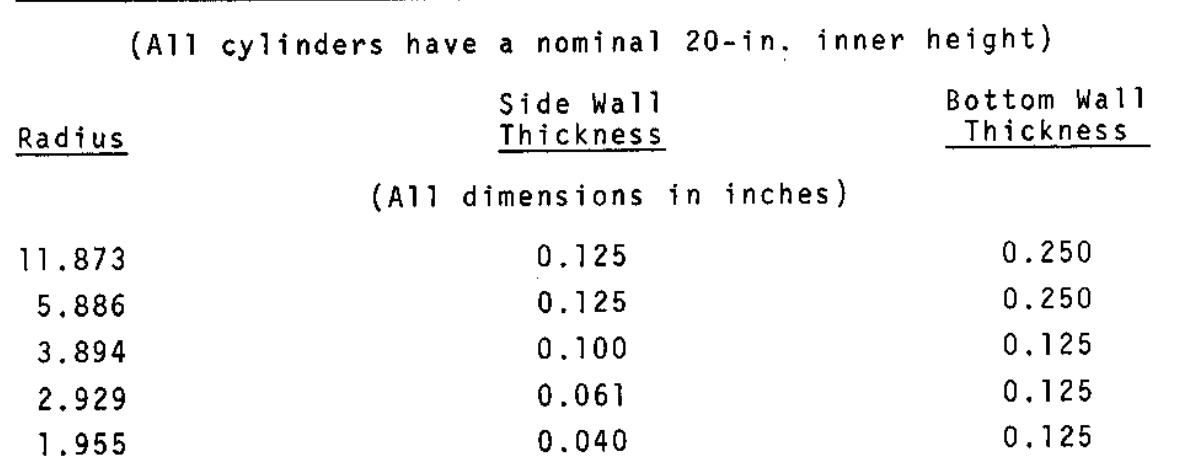

The neutron detector was placed on the bottom axis of the sample or at the half-height on the side. The detector was either an assemb1y of 10 decoupled counters (N. C. Wood) filled with 0.4 atm of ${ }^{10}{ }_{\mathrm{BF}_{3}}$ or a single counter (Texas Nuclear) filled with $10 \mathrm{~atm}$ of ${ }^{3} \mathrm{He}$. Counts were stored in 100 equally spaced time channels of a multichannel analyzer (RIDL 34-12B) with at least 30 of the final channels at the background level.

A computer code ( $\mathrm{PEX}^{19}$ ) based on Peierls' statistical method ${ }^{20}$ was used to determine the decay constant from the measured decays. This code features the use of the centroid rather than the midpoint of each counting interval, and the following choice of methods for eliminating background: if dark current is the only contributor, the code subtracts a constant value; if a background varies slowly compared to the desired counts, the code takes the difference between adjacent channels as the desired count, or takes the difference, by channel, between successive runs in which only the source-to-sample distance is varied. This last method is based on the condition common to most pulsed experiments - - the desired counts are strongly sensitive to the source-to-sample distance whereas the background of wall-return neutrons is nearly independent of this distance.

The deadtime of the recording system with a single $\mathrm{BF}_{3}$ counter was determined by the two-source technique to be considerably higher than that obtained with a double pulser for the electronics alone. Combining uncoupled $\mathrm{BF}_{3}$ counters enabled 
the system deadtime to approach the electronic deadtime of $1.7 \mu \mathrm{sec}$. A deadtime correction based on the appropriate twosource value was included in the analytical code.

The most serious problem faced in the experiment was wall return of epithermal neutrons. These neutrons are thermalized slowly because of the finite transit times in the room. If intercepted in the sample, they extend the decay and thus lower the $\lambda$ assignment. To minimize the effect, all experiments were performed inside a cadmium-1ined box with 2inch-thick walls of compacted $\mathrm{B}_{4} \mathrm{C}$ (Figure 2). Small sample experiments were performed in a relatively large room (6.5 feet to the floor and 10.5 feet to nearest wall), and the twoposition technique was used.

Special care was taken to minimize spatial harmonics. The angular component can be eliminated by placing the neutron source on the axis of the sample. Similarly, the first axial harmonic can be eliminated by placing the detector at the midplane. The degree of harmonic contribution also depends on the sample shape; the relative difference in the fundamental decay constant and that of the nearest harmonic is greatest when sample dimensions are nearly equal, i.e., harmonic contributions disappear fastest in regular geometries. Spherical shapes are ideal but are difficult to fabricate; as a compromise, graduated cylinders were used. The incomplete elimination of source harmonics (and incomplete thermalization as well) can be detected by noting the variation of the derived decay constant with the starting channel for a given set of data.

\section{The Pulsed Neutron Temperature Experiment}

The experimental technique was similar to that used in neutron total cross section studies ${ }^{2}$ (Figure 3 ). Two $\mathrm{BF}_{3}$ counters are wrapped in cadmium except for one end which opened into cadmium-collimated re-entry tubes in the pulsed medium. only neutrons originating from near the ends of re-entry tubes (placed in symmetric locations in a given sample) can pass 
through the neutron collimators. Two separate "detectordependent" transmissions, $\mathrm{Tr}_{A}$ and $\mathrm{Tr}_{\mathrm{B}}{ }^{22}$ are measured as functions of time by: placing a gold foil between the collimator and the detector of Unit $A$ while Unit $B$ is left open; pulsing the sample and observing the neutron die away in both counters; and then repeating with the foil moved to Unit $B$ while Unit $A$ is opened. Any effects of unbalanced counter efficiencies or of geometric asymmetries are automatically canceled by using the geometric mean for the reported transmission, $\operatorname{Tr}=\left(\operatorname{Tr}_{A} \operatorname{Tr}_{B}\right)^{\frac{1}{2}}$.

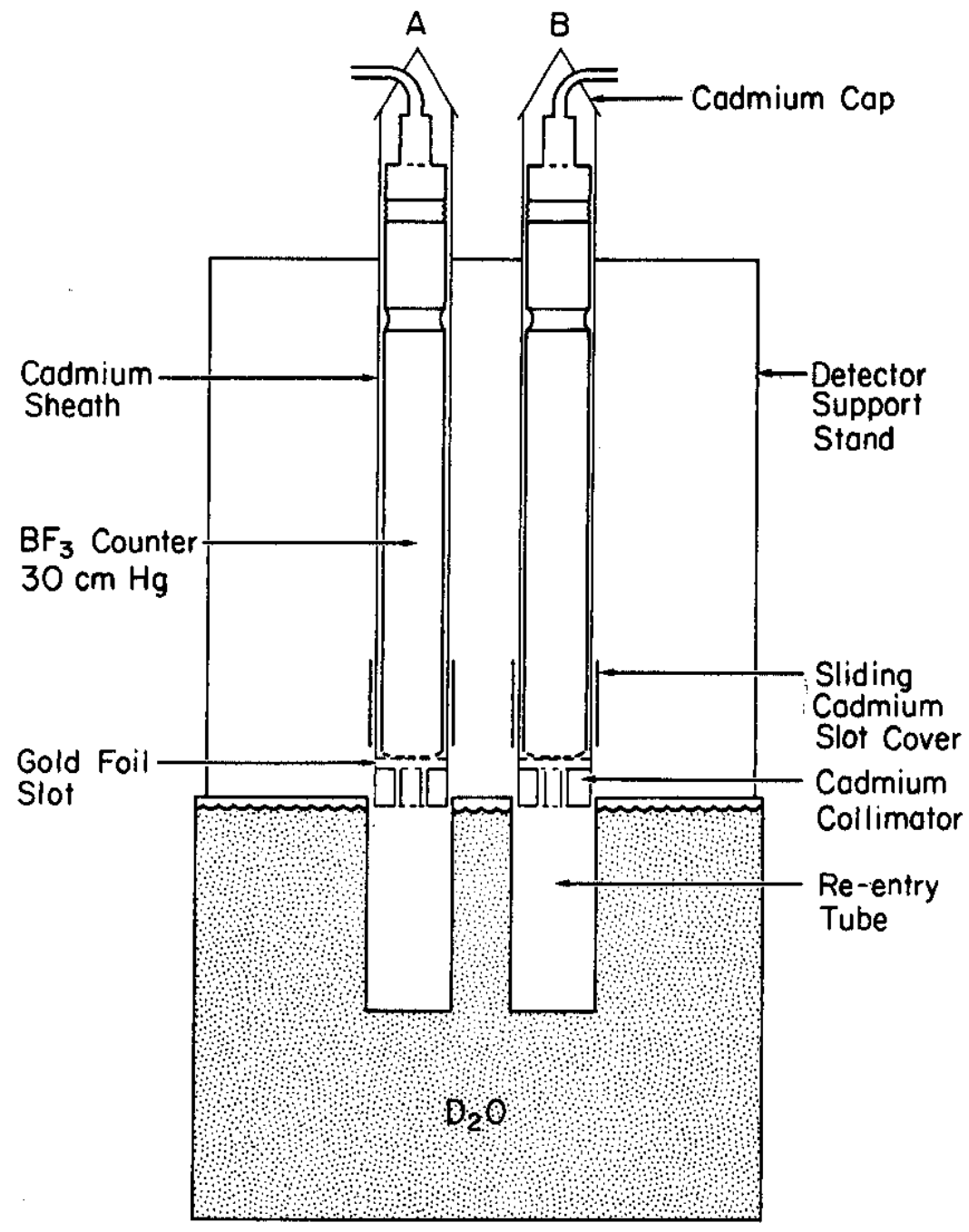

FIG. 3 PULSED NEUTRON TEMPERATURE EXPERIMENT 
These transmissions were converted to neutron temperatures by a calibration at identical pulsed conditions with the reentry tubes inserted into a paraffin sample at 295, 196, and $77^{\circ} \mathrm{K}$. The calibration sample was large enough so that diffusion cooling was negligible. The neutron spectrum measured is that of the equilibrium, or asymptotic, condition and coincides with that measured by time-of-flight methods using doublegating techniques. ${ }^{23}$

\section{Analysis of $\mathrm{H}_{2} \mathrm{O}$ Data}

Relaxation length measurements in poisoned $\mathrm{H}_{2} \mathrm{O}$ are summarized in Table II. The fundamental transverse buckling correction, $B_{11}^{2}(a, b)$ of Equation $1 b$, was less than $5 \%$ of $k^{2}$ for a 11 static $\mathrm{H}_{2} \mathrm{O}$ experiments; thus the effect of higher harmonics was small and was eliminated in least squares fits by successive dropping of data points near the source face.

The neutron temperature measurements on $\mathrm{H}_{2} \mathrm{O}$ are also tabulated in Table $I I$. The $R^{L u} / R^{1 / V}$ ratios are:

$$
\mathrm{R}^{\mathrm{Lu} / \mathrm{R}^{1 / v}}=\frac{\left({ }^{177} \text { Lu Act. }\right)^{\text {Test }} /\left({ }^{177} \text { Lu Act. }\right)^{\text {Ref. }}}{(1 / \mathrm{V} \text { Act. })^{\text {Test }} /(1 / \mathrm{VAct} .)^{\text {Ref. }}}
$$

'where the subcadmium activations in the test medium are normalized to the subcadmium activations in the thermal reference flux. Simultaneous irradiation and intermixing of foils on a single counting system allow the ratios of Equation 11 to be used with no correction.

The two pulsed measurements in $\mathrm{H}_{2} \mathrm{O}$ (Table II) were made primarily to check against Gon's ${ }^{21}$ measurements. Because of Gon's use of spherical geometry and an inherently effective method of handling wall-return neutrons, we considered the excellent agreement between our data and his (Figure 4) to be a sufficient check of our method. 
TABLE II

Static and Pulsed Measurements in $\mathrm{H}_{2} \mathrm{O}$

Inverse Diffusion Lengths and Neutron Temperatures in Borated $\mathrm{H}_{2} \mathrm{O}$ at $22^{\circ} \mathrm{C}$

Diffusion Length

$x^{2}$

\begin{tabular}{ll}
$\frac{\Sigma_{a}(B),}{\mathrm{cm}^{-1}}$ \\
\hline 0 & \\
0.00601 & \pm 0.00003 \\
0.01200 & \pm 0.00006 \\
0.0239 & \pm 0.0001 \\
0.0480 & \pm 0.0002 \\
0.0960 & \pm 0.0005 \\
0.0960 & \pm 0.0005 \\
0.7539 & \pm 0.0008 \\
0.205 & \pm 0.001 \\
0.272 & \pm 0.001 \\
0.272 & \pm 0.001 \\
0.361 & \pm 0.002
\end{tabular}

\section{Diffus}

$\frac{k^{2}, \mathrm{~cm}^{-2}}{0.136} \pm 0.002$
$0.169 \pm 0.002$
$0.206 \pm 0.003$
$0.276 \pm 0.003$
$0.417 \pm 0.005$
$0.694 \pm 0.009$
$0.690 \pm 0.009$
$0.994 \pm 0.013$
$1.23 \pm 0.02$
$1.56 \pm 0.02$
$1.54 \pm 0.02$
$1.98 \pm 0.03$

\begin{tabular}{c}
$\overline{\Sigma_{a}(B)+\Sigma_{a}\left(H_{2} \mathrm{O},\right.}$ \\
\hline $\mathrm{cm}^{-1}$ \\
\hline $6.10 \pm 0.08$ \\
$5.99 \pm 0.08$ \\
$6.03 \pm 0.08$ \\
$6.00 \pm 0.08$ \\
$5.95 \pm 0.08$ \\
$5.87 \pm 0.08$ \\
$5.84 \pm 0.08$ \\
$5.64 \pm 0.08$ \\
$5.41 \pm 0.08$ \\
$5.29 \pm 0.08$ \\
$5.22 \pm 0.08$ \\
$5.17 \pm 0.08$
\end{tabular}

Distance
in Tank

in Tank,

$\frac{i n}{2.0}$

$\frac{R^{L U} / R^{1 / v}}{1.00}$

Neutron Temperature

$\begin{array}{ccc}- & - & - \\ - & - & - \\ - & - & -\end{array}$

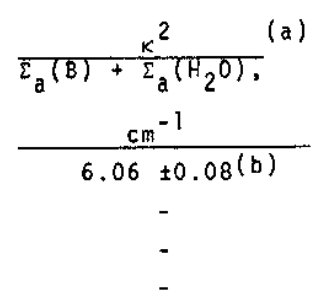

1.5

1.06

$1.05 \pm 0.01$

1.5

1.11

$1.09 \pm 0.02$

1.5

1.09

$1.07 \pm 0.02$

1.5

1.10

$1.08 \pm 0.02$

1.0

1.21

$1.17 \pm 0.03$

1.0

1.24

1. $20 \pm 0.03$

1.0

1.20

$1.16 \pm 0.03$

1.0

1.29

$1.24 \pm 0.03$

$5.90 \pm 0.08$

$5.73 \pm 0.10$

$5.83 \pm 0.10$

$5.86 \pm 0.10$

$5.47 \pm 0.12$

$5.41 \pm 0.12$

$5.61 \pm 0.12$

$5.35 \pm 0.12$

Pulsed Decay Constants in $\mathrm{H}_{2} \mathrm{O}$ at $24.6^{\circ} \mathrm{C}$

$$
\begin{array}{ccc}
\text { Sample } & \begin{array}{c}
\text { Radius, } \\
\text { in. }
\end{array} & \frac{\text { Height, }}{\text { in. }} \\
2 & \begin{array}{c}
3.894 \\
1.955
\end{array} & \begin{array}{c}
6.020 \\
3.930
\end{array}
\end{array}
$$

$\begin{array}{cc}\text { Pulsed Decay Constants in } & \begin{array}{c}\text { Convergence } \\ \text { Time to } \\ \text { Asymptotic } \\ \text { Decay, }\end{array} \\ \begin{array}{l}\text { Counter } \\ \text { and } \\ \text { position }\end{array} & \begin{array}{c}\text { usec } \\ \mathrm{BF}_{3} \text { sfde }\end{array} \\ \mathrm{BF}_{3} \text { side } & 600 \\ & 450\end{array}$

Final Buckling. $\frac{\mathrm{cm}^{-2}}{0.09470}$ 0.29722 $\kappa^{2} / \Sigma_{a}\left(20^{\circ} \mathrm{C}\right)$

$\frac{\mathrm{cm}^{-1}}{6.13 \pm 0.03}$

(a) $\mathrm{P}_{3}$ Approximation, Equation 8 .

(b) Normalized at $\Sigma_{a}(B)=0$ to the least squares fit of the relaxation length data. 


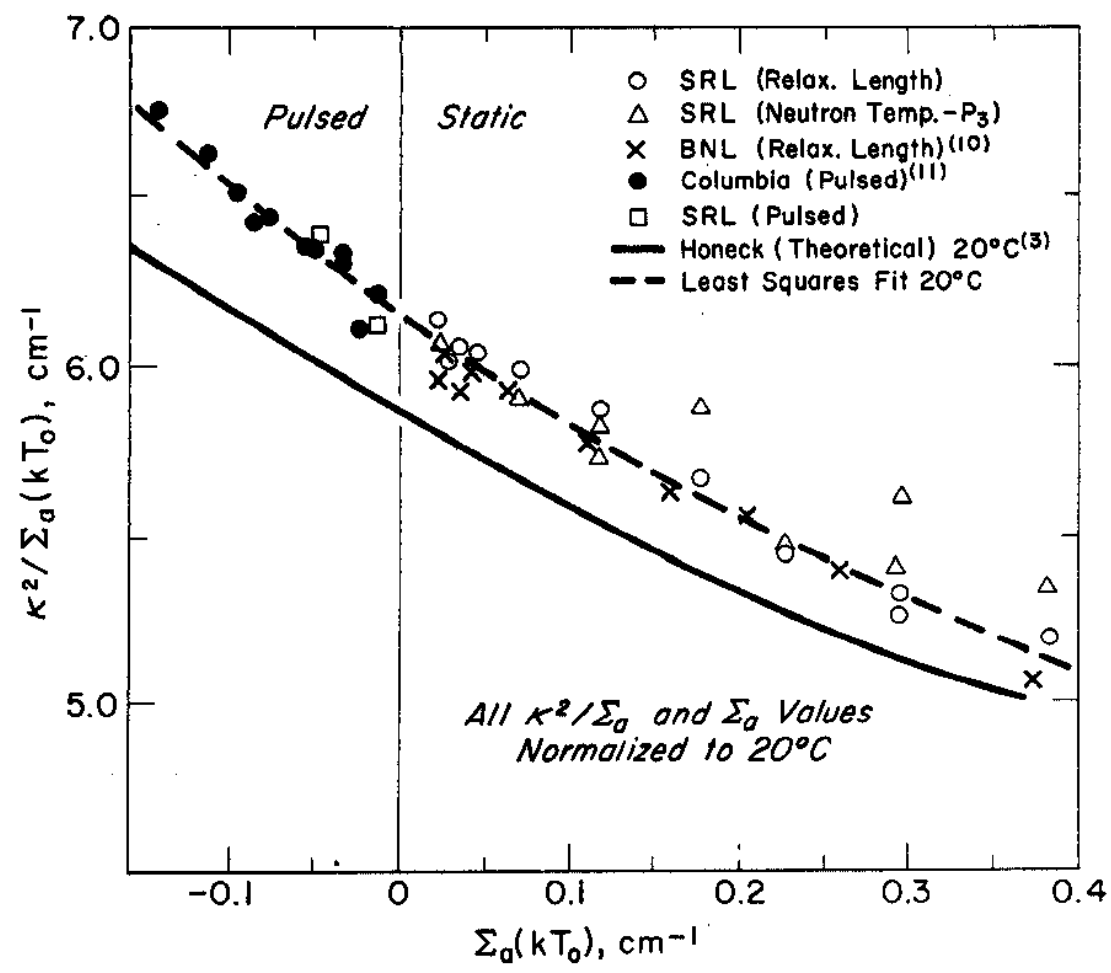

FIG. 4 COMPARISON OF EXPERIMENTAL DATA TO THEORETICAL CALCULATIONS FOR $\mathrm{H}_{2} \mathrm{O} \quad\left(\mathrm{T}_{0}=\right.$ moderator temperature $\left.=20^{\circ} \mathrm{C}\right)$

A11 SRL data along with Starr and Koppel's (BNL) static data ${ }^{10}$ and Gon's (Columbia) pulsed data are shown in Figure 4. The BNL data have been recomputed using a best value ${ }^{2}$ of 0.332 barns for the absorption cross section of hydrogen and 759 barns for boron. (It is believed that the hydrogen cross section is known far more accurately than it can be derived from a single experiment of this nature.) The static results of Bretscher and Meyer, ${ }^{24}$ although not shown on Figure 4 , agree with our measurements and the BNL results, but are more scattered.

To display the static spectral index measurements on Figure 4 , they had first to be converted to neutron temperatures. ${ }^{17}$ These temperatures were then used to derive $\kappa^{2}$ from Equation 10. Equations 7 and 8 were used to evaluate $D_{\text {eff }}$ with the result at $\Sigma_{a}(B)=0$ normalized to the experimental curve in Figure 4 . If the $P_{1}$ approximation instead of $P_{3}$ had been used, the spectral index data in Figure 4 would have been more consistent. 
The combined pulsed and static data in Figure 4 deviated from Honeck's calculations in the zero poison intercept. The slope, however, has been closely predicted. All the data in Figure 4 except the spectral index data have been used in a three-parameter least squares fit to Equation 3 . The best fit parameters at a temperature of $20^{\circ} \mathrm{C}$ are:

$$
\begin{aligned}
& \alpha_{1}=6.155 \mathrm{~cm}^{-1} \\
& \alpha_{2}=3.51 \\
& \alpha_{3}=2.2 \mathrm{~cm}^{+1}
\end{aligned}
$$

These transform to the usual pulsed parameters:

$$
\begin{aligned}
& D_{0}=3.57 \pm 0.04 \times 10^{4} \mathrm{~cm}^{2} \mathrm{sec}^{-1} \\
& C=3.31 \pm 0.15 \times 10^{3} \mathrm{~cm}^{4} \mathrm{sec}^{-1} \\
& F=2.8 \pm 0.7 \times 10^{2} \mathrm{~cm}^{6} \mathrm{sec}^{-1}
\end{aligned}
$$

Systematic errors which may be present in cross section assignments are not included in the above error bars.

\section{Analysis of $\mathrm{D}_{2} \mathrm{O}$ Data}

Relaxation length measurements in 1 ight-to-intermediate poisoned $\mathrm{D}_{2} \mathrm{O}$ are summarized in Table III and in heavily poisoned $\mathrm{D}_{2} \mathrm{O}$ in Table V. For $\mathrm{D}_{2} \mathrm{O}$, the effect of higher order harmonics was large; therefore, harmonic amplitude coefficients (the $A_{m n}$ of Equation 1) had to be determined. A set of coefficients was determined by fitting Equation 1 to the unpoisoned flux distributions using the previously measured ${ }^{1}$ value of $k(0)$. A three-parameter fit for the three dominant amplitudes, $A_{11}$, $A_{13}=A_{31}$, and $A_{15}=A_{51}$, was determined. These derived amplitudes were used to eliminate the harmonic content of the measured data. The resulting $k$ values of the intermediate poisoned samples agree well with those derived by successive dropping 
of data points. In heavily poisoned $\mathrm{D}_{2} \mathrm{O}$, the dependence on $\mathrm{K}(0)$ becomes sma11, and for $\Sigma_{a}>0.05 \mathrm{~cm}^{-1}$, variations as large as $5 \%$ in the assumed reference value affected the quoted $\kappa^{2}$ only slightly.

TABLE III

Inverse Diffusion Lengths and Neutron Temperatures in Borated $D_{2} \mathrm{O}$

\begin{tabular}{|c|c|c|c|c|c|c|c|c|c|c|c|c|c|}
\hline \multirow{2}{*}{\multicolumn{2}{|c|}{$\Sigma_{a}(8), \mathrm{cm}^{-1}$}} & \multirow[b]{2}{*}{$\begin{array}{r}\mathrm{D}_{2} \mathrm{O} \\
\text { Purity, } \\
\text { mol \% }\end{array}$} & \multirow[b]{2}{*}{$\begin{array}{l}\text { Sample } \\
\text { Temp, } \\
\text { oC } \\
\end{array}$} & \multicolumn{4}{|c|}{ Diffusion Length } & \multicolumn{6}{|c|}{ Neutron Temperature } \\
\hline & & & & $k^{2}$ & $\mathrm{~cm}^{-2}$ & $\overline{\Sigma_{a}(8)}$ & , & $\begin{array}{c}\text { Distance } \\
\text { in Tank, } \\
\text { in. } \\
\end{array}$ & $R^{L U} / R^{1 / v}$ & $\underline{n}^{\prime} / T_{0}$ & $\underline{T}_{n(\infty)}$ & $2^{\prime T_{0}^{(b)}}$ & $\begin{array}{c}\kappa_{a}^{2}(\mathrm{~B})+\Sigma_{a}\left(\mathrm{D}_{2} 0\right) \\
\mathrm{cm}^{-1}\end{array}$ \\
\hline 0 & & 99.84 & $\overline{22.0}$ & 0.000083 & (a) & 1.049 & & 12 & 0.99 & $\overline{0.99}$ & 0.99 & \pm 0.01 & $1.06 \pm 0.01$ \\
\hline 0.00583 & \pm 0.00004 & 99.84 & 22.1 & 0.00604 & \pm 0.00011 & 1.04 & \pm 0.02 & 12 & 0.99 & 0.99 & 0.99 & \pm 0.01 & $1.06 \pm 0.01$ \\
\hline 0.0142 & \pm 0.0001 & 99.84 & 22.5 & 0.0144 & \pm 0.0003 & 1.02 & \pm 0.02 & 6.3 & 1.12 & 1.10 & 1.10 & \pm 0.02 & $1.01 \pm 0.01$ \\
\hline 0.0230 & \pm 0.0002 & 99.83 & 22.8 & 0.0228 & \pm 0.0005 & 0.99 & \pm 0.02 & 4.8 & 1.13 & 1.11 & 1.11 & \pm 0.02 & $1.00 \pm 0.01$ \\
\hline 0.0401 & \pm 0.0003 & 99.83 & 22.1 & 0.0378 & $\pm 0,0008$ & 0.94 & \pm 0.02 & 6.3 & 1.18 & 1.15 & 1.15 & \pm 0.02 & $.99 \pm 0.01$ \\
\hline 0.0583 & \pm 0.0004 & 99.82 & 22.5 & 0.0556 & \pm 0.0012 & 0.95 & \pm 0.02 & 3.2 & 1.25 & 1.21 & 1.22 & \pm 0.03 & $.97 \pm 0.02$ \\
\hline
\end{tabular}

\footnotetext{
(a) Reference (1)

(b) Corrected to Asymptotic Value

(c) $P_{3}$ Approximation, Equation 8 .
}

Axial activation profiles are plotted in Figure 5 for a nonpoisoned, a lightly poisoned, and the three most heavily poisoned $\mathrm{D}_{2} \mathrm{O}$ samples. These are shown as ratios of measured-toanalytic fitted activities. The harmonic correction is that required to systematize the data for $\Sigma_{a}(B)=0$ and $0.023 \mathrm{~cm}^{-1}$. The data for heavily poisoned $\mathrm{D}_{2} \mathrm{O}$ is discussed in a later section.

To obtain the relaxation times from the pulsed measurements and the geometrical bucklings, special analytical techniques were required since in $\mathrm{D}_{2} \mathrm{O}$ the magnitude of the extrapolation distance is significant. In determining the extrapolation distances, the reflection effect of the aluminum walls, changes 


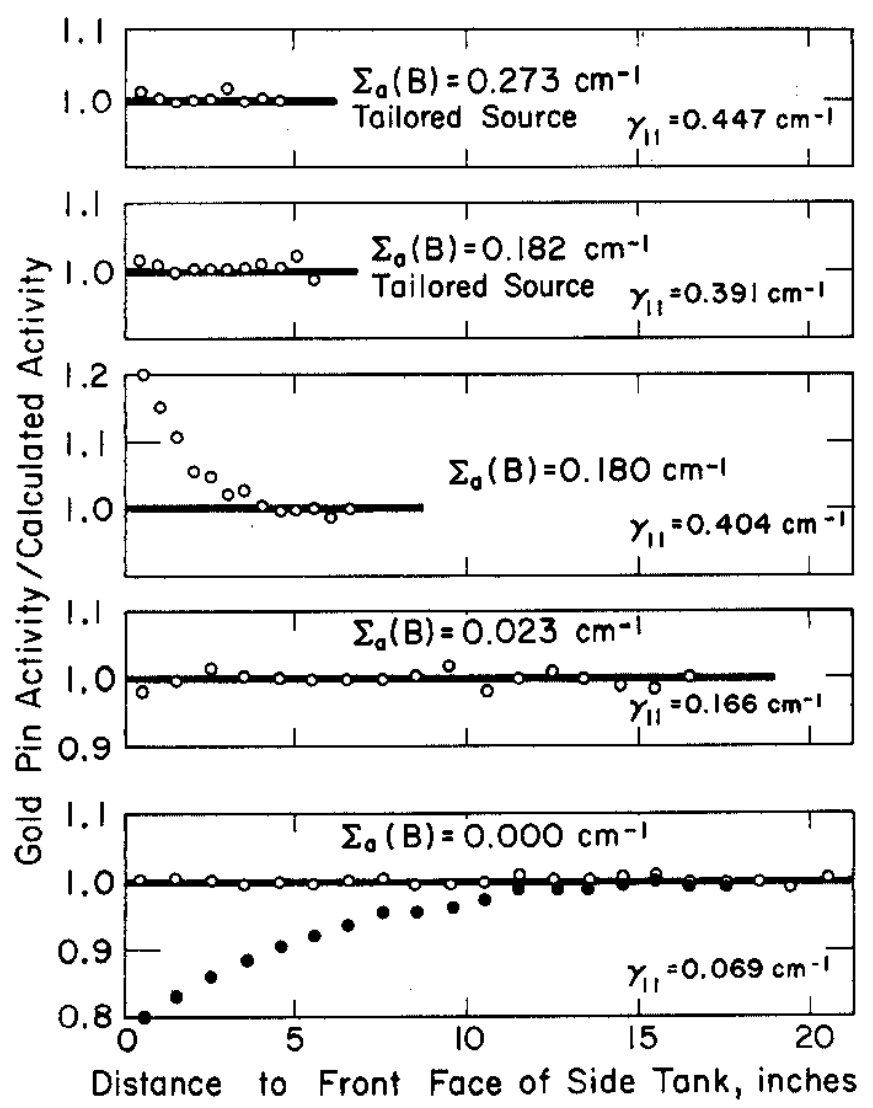

- First 5 Harmonics Included - Only Fundamental Included

FIG. 5 APPROACH TO EQUILIBRIUM IN RELAXATION LENGTH MEASUREMENTS ON BORATED $\mathrm{D}_{2} \mathrm{O}$

in radial extrapolations due to curvature of the walls, ${ }^{25}$ and the change of transport mean free path with sample size due to spectral cooling were included. Small changes in temperature and moderator purity during the experiment were also corrected for. Our expression for the radial extrapolation distance in terms of the slab distance was taken from Flatt and Baller. ${ }^{25}$ The extrapolation distance is estimated initially to compute $\frac{\lambda-\lambda}{\mathrm{B}^{2}}$. This is then identified as $(\mathrm{VD})$ eff, and the computation is iterated with the new extrapolation distance which can be obtained from the extraction of $\mathrm{D}_{\text {eff }}$. The iterative procedure is detailed in the Appendix. Two neutron temperature determinations were also made by pulsed methods. These data and all the relaxation time measurements are listed in Table IV. 
TABLE IV

Pulsed Measurements in $\mathrm{D}_{2} \mathrm{O}$

Pulsed Decay Constants in $\mathrm{O}_{2} \mathrm{O}$

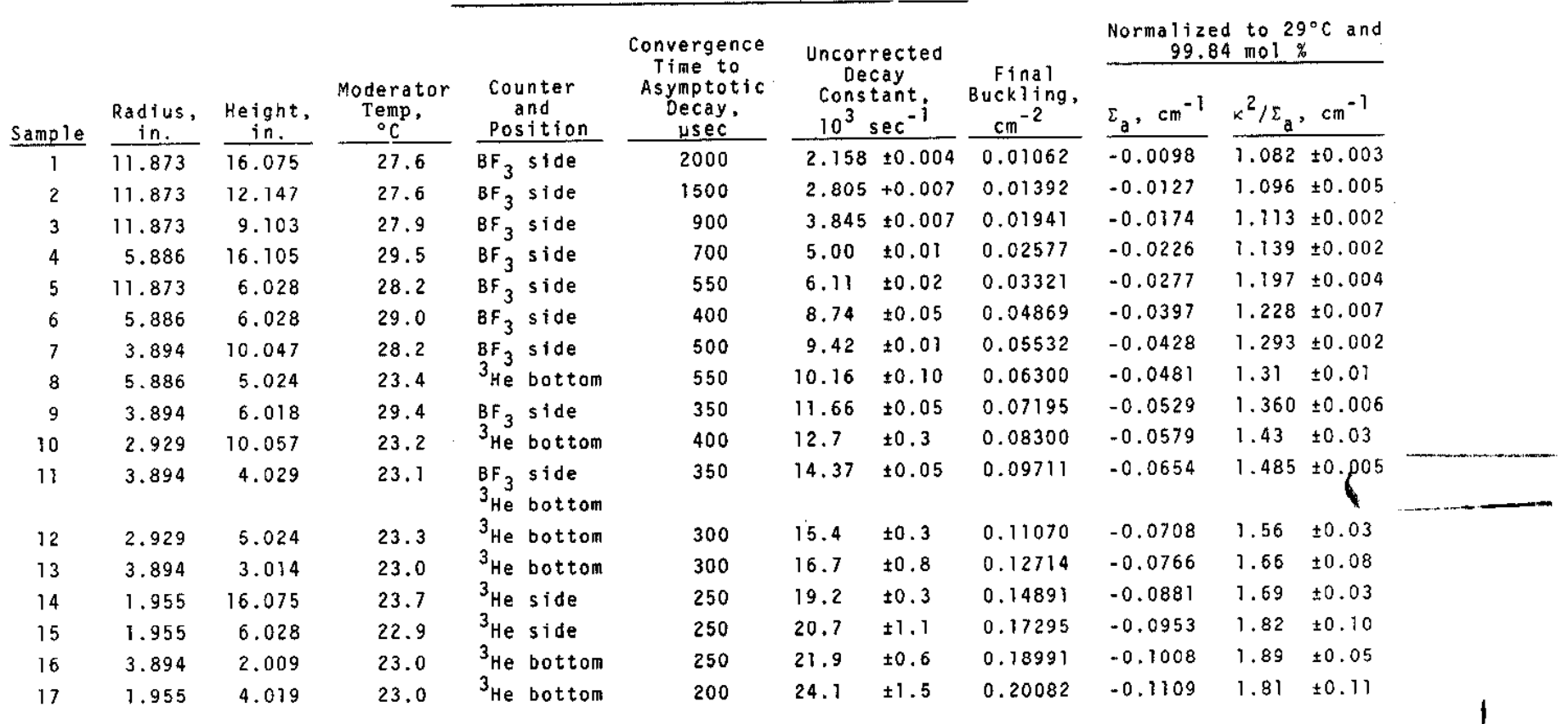

Pulsed Neutron Temperatures in $D_{2} \mathrm{O}$ at $24.7^{\circ} \mathrm{C}$

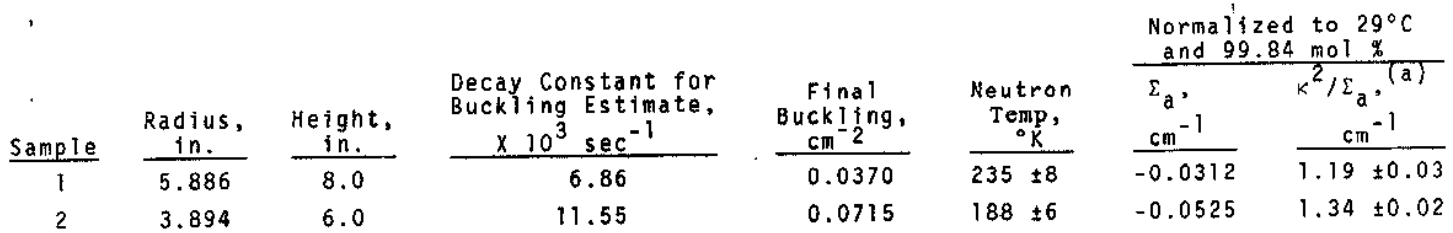

(a) $P_{3}$ Approximation, Equation 9. 
The combined, but unnormalized, pulsed and static data in Figure 6 agree reasonably well with Honeck's calculations ${ }^{3}$ over a restricted range near the origin. The cause of disagreement with theory at small pulsed samples (large negative absorption cross sections) is not clear. The data may disagree because Honeck's pulsed computations were actually static computations transformed by the equivalence relations, Equations 5 and 6 ; the range of validity of Equation 6 may be severely limited. Also, since the pulsed neutron temperature measurements agree better with experimental decay times than with theory, the disagreement may arise because the theory failed to properly predict the neutron spectrum. Recently Ghatak and Honeck ${ }^{26}$ made a series of computations for graphite in which the neutron density was treated as a nonseparable function of time and energy. The resultant values of $\kappa^{2} / \Sigma_{a}$ at high bucklings were larger than those found in previous energy-independent studies and agreed better with the data of Starr and Price. ${ }^{27}$ A similar calculation for $\mathrm{D}_{2} \mathrm{O}$ could have the same effect. Still another cause for disagreement might be that the pulsed data asymptotically approached a possible Corngold $\lambda=\left(v \Sigma_{t}\right)_{\text {min }}$ limit, which is depicted in Figure 6 .

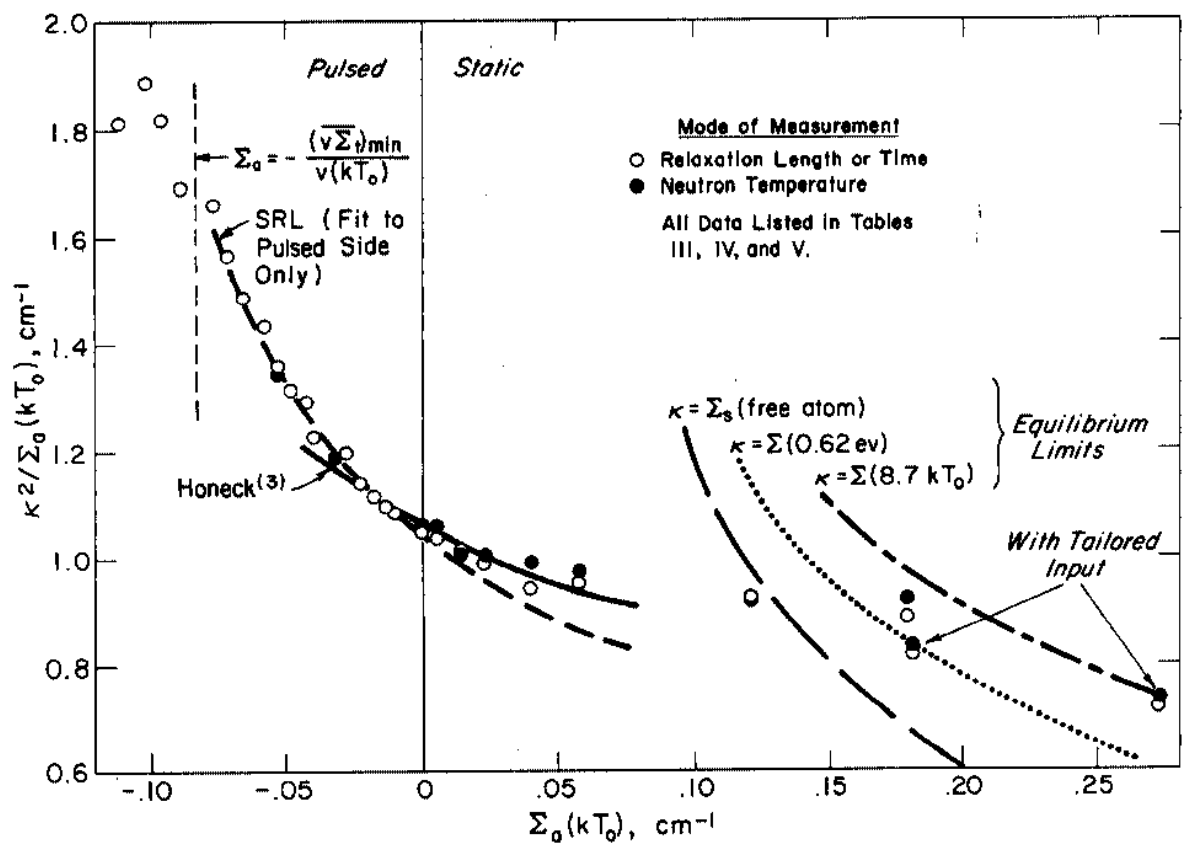

FIG. 6 COMPARISON OF EXPERIMENTAL DATA TO THEORETICAL CALCULATIONS FOR $\mathrm{D}_{2} \mathrm{O}$ $\left(T_{0}=\right.$ moderator temperature as listed in Tables III, IV, and V) 
It did not seem that systematic errors would explain the discrepancy. The pulsed results could have been erroneous had an asymptotic energy equilibrium not been reached. However, the direction of the required correction is such that the disagreement between experiment and theory increases. Moreover, correcting for a possible failure to reach spatial equilibrium would only remove the internal consistency of the data. Our experience shows the discrepancy may also result from failure to have completely eliminated wall-return neutrons. However, in the $\mathrm{H}_{2} \mathrm{O}$ work, where wall return was particularly evident, our results agreed quite well with the data of Gon et a1., 1 who by the unique design of their experiment should have eliminated practically all wall return.

If a weighted least squares analysis is performed on all our normalized pulsed data with only the experimental errors in the $\lambda$ measurements being considered, the diffusion parameters at $29.0^{\circ} \mathrm{C}$ and $99.84 \mathrm{~mol} \% \mathrm{D}_{2} \mathrm{O}$ are:

$$
\begin{aligned}
& D_{O}=2.12 \pm 0.02 \times 10^{5} \mathrm{~cm}^{2} \mathrm{sec}^{-1} \\
& C=8.1 \pm 0.3 \times 10^{5} \mathrm{~cm}^{4} \mathrm{sec}^{-1} \\
& F=16 \pm 4 \times 10^{5} \mathrm{~cm}^{6} \mathrm{sec}^{-1}
\end{aligned}
$$

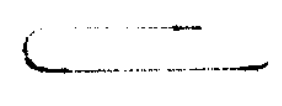

In Figure 6 this $\mathrm{fit}$ is indicated by a dashed 1 ine; however, an extension into the static region indicates that these parameters are not adequate. Since we should avoid using data that approaches either the pulsed or static Corngold limits, we have used data between $\Sigma_{a}=-0.04$ and $+0.04 \mathrm{~cm}^{-1}$ for extracting the best parametric fit to the combined pulsed and static data. Pulsed and static data were normalized to $29^{\circ} \mathrm{C}$ using Equation 7. These normalized data and least squares fit are shown in

Figure 7 ; the best fit parameters at $99.84 \mathrm{~mol}: \mathrm{D}_{2} \mathrm{O}$ and $29^{\circ} \mathrm{C}$ are:

$$
\begin{aligned}
& \alpha_{1}=1.054 \mathrm{~cm}^{-1} \\
& \alpha_{2}=3.42 \\
& \alpha_{3}=29.1 \mathrm{~cm}^{+1}
\end{aligned}
$$




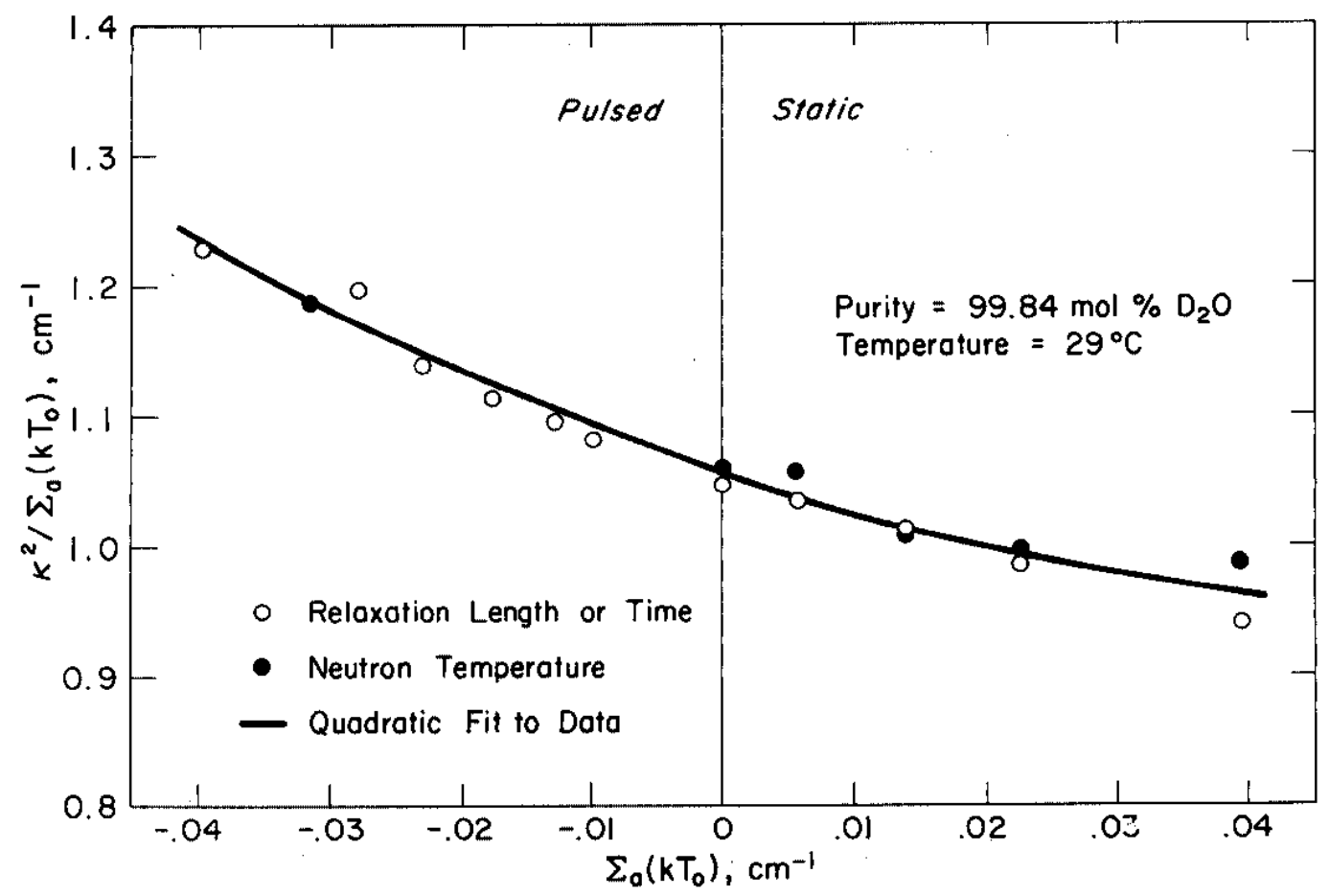

FIG. 7 RESTRICTED RANGE EXPERIMENTAL DATA IN $\mathrm{D}_{2} \mathrm{O}$ $\left(T_{0}=\right.$ moderator temperoture $\left.=29^{\circ} \mathrm{C}\right)$

These transform to the usual pulsed parameters:

$$
\begin{aligned}
& D_{0}=2.12 \pm 0.02 \times 10^{5} \mathrm{~cm}^{2} \mathrm{sec}^{-1} \\
& \mathrm{C}=6.5 \pm 0.3 \times 10^{5} \mathrm{~cm}^{4} \mathrm{sec}^{-1} \\
& \mathrm{~F}=-13 \pm 10 \times 10^{5} \mathrm{~cm}^{6} \mathrm{sec}^{-1}
\end{aligned}
$$

We have corrected these coefficients to 100 mol $: \mathrm{D}_{2} \mathrm{O}$ and $20^{\circ} \mathrm{C}$. While the $\mathrm{D}_{0}$ correction is straightforward, the $\mathrm{C}$ correction is uncertain. We have used the computations of Honeck and Michae $1^{2}$ for the temperature variation of $C$ and Paulk's ${ }^{28}$ experimental data for the isotopic purity correction. The obviously poorly determined $F$ was not corrected. Our final normalized values at $100 \mathrm{~mol} \% \mathrm{D}_{2} \mathrm{O}$ and $20^{\circ} \mathrm{C}$ are:

$$
\begin{aligned}
& D_{O}=2.09 \pm 0.02 \times 10^{5} \mathrm{~cm}^{2} \mathrm{sec}^{-1} \\
& C=6.6 \pm 0.3 \times 10^{5} \mathrm{~cm}^{4} \mathrm{sec}^{-1}
\end{aligned}
$$




\section{SPECIAL STATIC EXPERIMENTS}

\section{Dependence on Source Conditions in $\mathrm{H}_{2} \mathrm{O}$}

$$
\text { For } \mathrm{H}_{2} \mathrm{O} \text { the term } 4 \bar{\mu}_{0} \text { in Equation } 8 \text { is greater than unity, }
$$
and the $P_{n}$ series approximation does not converge rapidly. Thus substituting Equation 8 into Equation 7 does not give a satisfactory expression for the dependence of $k$ on neutron temperature; thus calculated and experimental neutron spectra should be compared directly. Such a comparison is shown in Figure 8 . In the Monte Carlo calculations, ${ }^{8}$ Brown's temperatures ${ }^{29}$ are used which were obtained by least square fitting a Maxwellian distribution. The THERMOS ${ }^{9}$ temperature ratios are proportional to $\overline{\mathrm{v}}^{2}$, the square of the neutron velocities averaged over the neutron density in the energy interval 0 to $0.14 \mathrm{ev}$. Figure 8 clearly shows that source conditions do not strongly affect the calculated spectral shifts. The following paragraphs show that the experimental data, if properly interpreted, support the theoretical results.

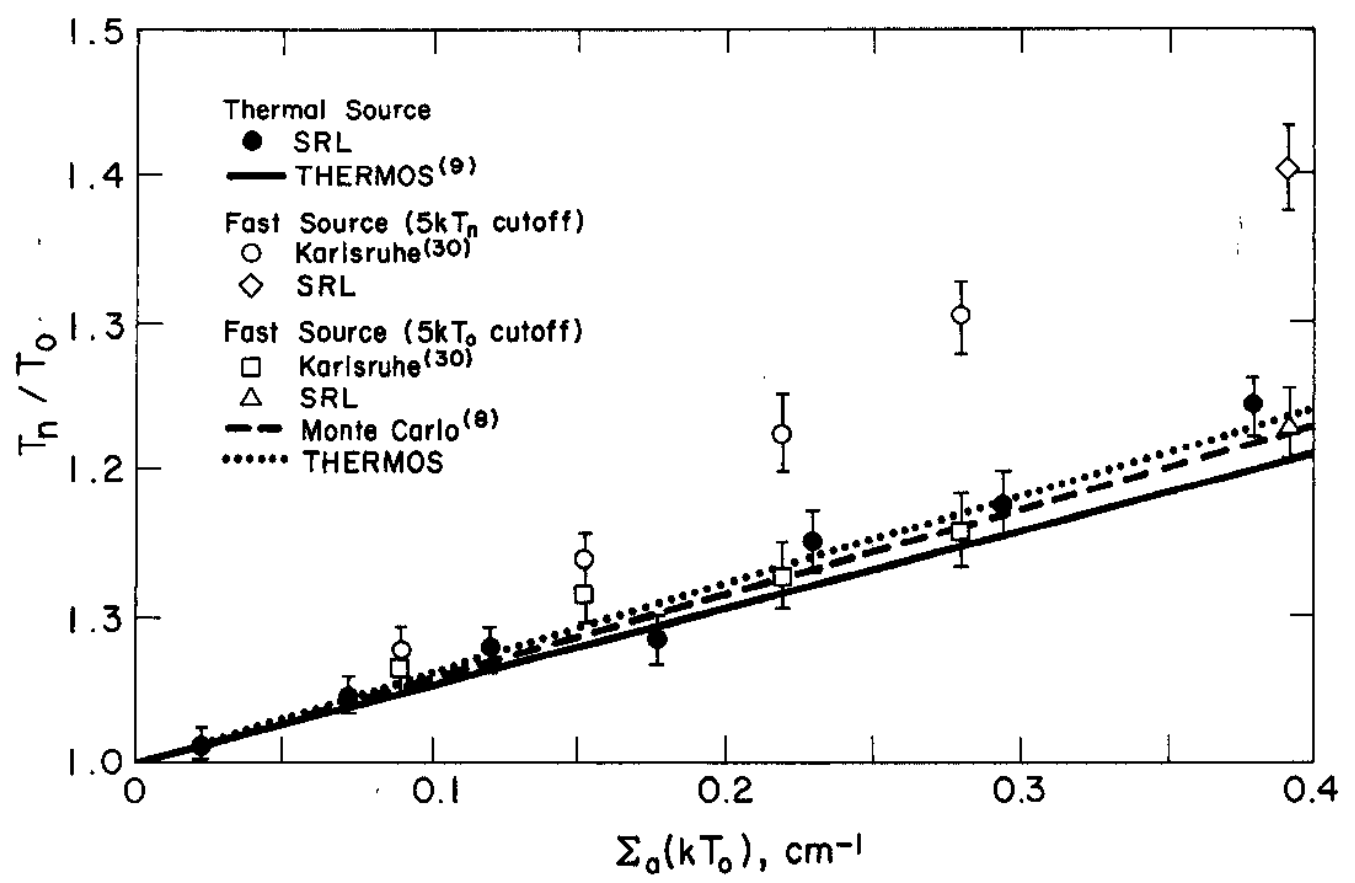

FIG. 8 COMPARISON OF ASYMPTOTIC NEUTRON TEMPERATURES DERIVED FROM SPECTRAL INDEX MEASUREMENTS AND THEORETICAL CALCULATIONS FOR $\mathrm{H}_{2} \mathrm{O}$ 
During the course of our experiments, similar activation temperature measurements were also being made at Karlsruhe by Burkart. ${ }^{30}$ The neutron temperature ratios derived by Burkart are shown in Figure 8 as the open circles. His absorption hardened temperatures are nearly a factor of two higher than those measured at SRL. In attempting to reconcile this discrepancy, experimental differences were noted between the SRL and Karlsruhe studies. The SRL source was essentially a thermal neutron source, the neutrons being supplied by diffusion. In contrast, the low cadmium ratios reported by Burkart indicate a very high epithermal component, in fact, indistinguishable from that for a multiplying medium ${ }^{3}$ having the same thermal neutron absorption cross sections. Further, Burkart used cadmium pillboxes rather than a shutter for the epithermal correction. As a test of Burkart's data, a single measurement was made at SRL on a heavily poisoned $\mathrm{H}_{2} \mathrm{O}$ sample fed by a pure slowingdown source, which was obtained by covering a 4-inch-diameter cylinder with cadmium and irradiating it in a mixed fastthermal flux. Bare and cadmium-covered ( $p$ illbox) lutetium and copper foils were placed along the axis of the cylinder. As shown in Figure 8 , the data point, $\diamond$, from this experiment fits smoothly onto Burkart's data. The measured cadmium ratio also fits a linear extension of his data.

In correcting for the effect of epithermal neutrons, Burkart used Westcott's method ${ }^{32}$ and the derived neutron temperature, $\mathrm{T}_{\mathrm{n}}$, to determine the cutoff energy separating the thermal flux from the $1 / E$ epithermal flux. Because absorption hardening only depletes the low energy end of the distribution, the use of this increased cutoff energy is questionable. If Burkart's data are reanalyzed using $T_{0}$ rather than $T_{n}$, the derived neutron temperatures are strongly reduced and, as shown in Figure 8 , they then lie somewhat below those measured at SRL.

Our interpretation is further supported by THERMOS computations for the $\Sigma_{a}(B)=0.371 \mathrm{~cm}^{-1}$ entry in Table $V$. The calculation gives the same neutron temperature ratio, $\mathrm{T}_{\mathrm{n}} / \mathrm{T}_{0}=1.23$, as given by the Wescott analysis using $T_{0}$ for the cutoff, 
IABLE V

Special Static Experiments

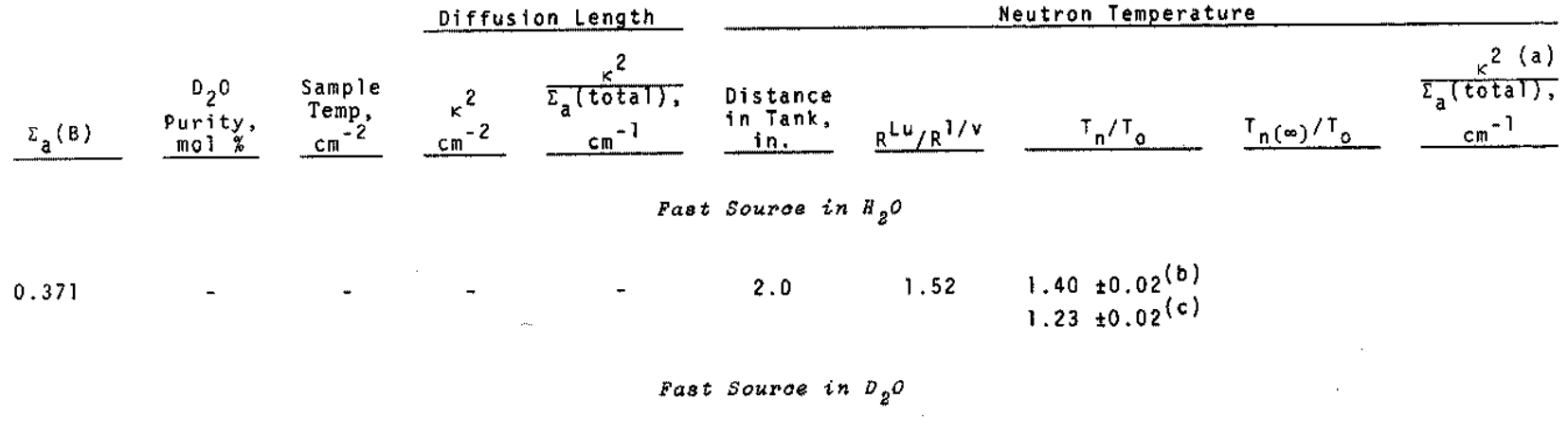

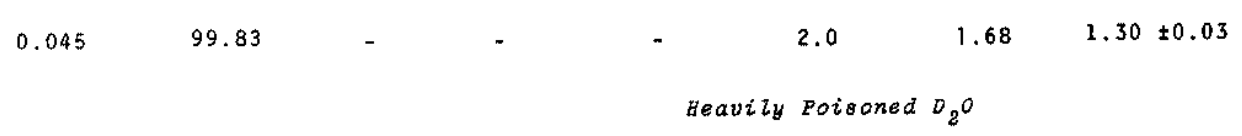

\begin{tabular}{|c|c|c|c|c|c|c|c|c|c|c|}
\hline $0.121^{(d)}$ & 99.80 & 23.6 & 0.1116 & 0.924 & 2.1 & 1.41 & 1.34 & 1.44 & \pm 0.04 & $0.92 \pm 0.02$ \\
\hline $0.180^{(d)}$ & 99.78 & - & 0.1589 & 0.883 & 2.3 & 1.42 & 1.36 & 1.57 & \pm 0.05 & $0.92 \pm 0.02$ \\
\hline $0.182^{(e)}$ & 99.72 & 26.5 & 0.1480 & 0.813 & 2.4 & 1.82 & - & 1.74 & \pm 0.02 & $0.83 \pm 0.02$ \\
\hline $0.273^{(e)}$ & 99.68 & 31.5 & 0.1950 & 0.715 & 2.4 & 2.20 & - & 2.25 & \pm 0.10 & $0.74 \pm 0.03$ \\
\hline
\end{tabular}

\footnotetext{
(a) $p_{3}$ Approximation, Equation 8 .

(b) $T_{n}$ Cutoff

(c) $T_{0}$ cutoff

(d) Thermal source

(e) Tailored source
} 
and also predicts a value of $R=1.47$, within $3 \%$ of the measured subcadmium activation ratio.

\section{Dependence on Source Conditions in $\mathrm{D}_{2} \mathrm{O}$}

The strong dependence of the neutron spectrum on the source feed for poisoned $\mathrm{D}_{2} \mathrm{O}$ is shown in Figure 9 . This figure shows Monte Carlo computations ${ }^{3} 3$ and THERMOS computations for poisoned $\mathrm{D}_{2} \mathrm{O}$ with fast and thermal sources. In the THERMOS computations, the thermal source condition was obtained by a multiregion computation having a source-free poisoned region. As with $\mathrm{H}_{2} \mathrm{O}$, the two computational methods agree closely but, unlike the $\mathrm{H}_{2} \mathrm{O}$ case, both methods now show a marked dependence on the source feed.

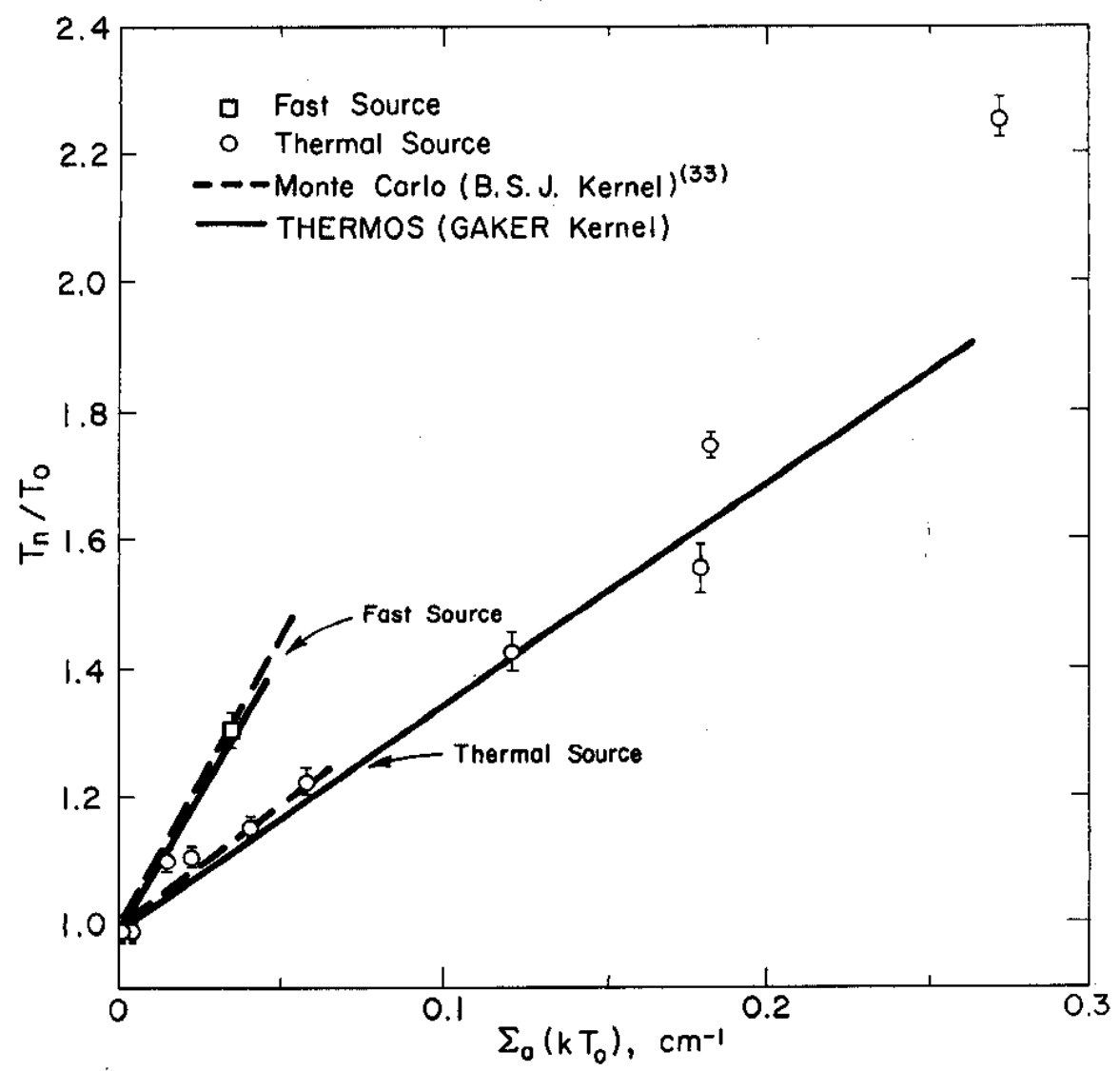

FIG. 9 COMPARISON OF ASYMPTOTIC NEUTRON TEMPERATURES DERIVED FROM SPECTRAL INDEX MEASUREMENTS AND THEORETICAL CALCULATIONS FOR $\mathrm{D}_{2} \mathrm{O}$ 
The neutron temperature ratios derived from the lutetium activations agree reasonably well with the computed temperature ratios over the entire range. The intermediate ratios include THERMOS computed corrections to the measured ratios to account for the nonasymptotic energy distribution at the foil position. These corrections are the differences between the $\mathrm{T}_{\mathrm{n}(\infty)} / \mathrm{T}_{0}$ and $\mathrm{T}_{\mathrm{n}} / \mathrm{T}_{\mathrm{O}}$ columns of Table III.

A single measurement with an epithermal energy feed was made in the smal1 4 -inch-diameter cadmium-covered container at $\Sigma_{\mathrm{a}}=0.0450 \mathrm{~cm}^{-1}$. Interpreting the measured activation ratios as neutron temperatures by the Westcott method failed completely because the method was inadequate to treat the spectrum in the 0.1 to $0.6 \mathrm{ev}$ energy interval. Instead, the neutron temperature is inferred from the measurements by THERMOS computations. This is accomplished by first finding an absorption cross section such that the THERMOS predicted activation ratio for the small sample matches that of the experiment as listed in Table $V$. This same cross section is used in a second computation that assumes no leakage. The neutron temperature for the infinite case is then determined from the average neutron velocity given by the second computation. The temperature thus derived from the measurement is (Figure 9) consistent with both of the depicted computational methods.

\section{A Test of the Theoretical Equilibrium Limit in $\mathrm{D}_{2} \mathrm{O}$}

The most heavily poisoned cases $\left(\Sigma_{\mathrm{a}}>0.12 \mathrm{~cm}^{-1}\right)$ are particularly interesting since a formal equilibrium limit for the solution of the Boltzmann equation is either approached or exceeded. ${ }^{7}$ In the past, this limit has been interpreted to mean that higher asymptotic values of $x$ could not be obtained experimentally. In an effort to examine this region, we performed tests at three poison concentrations. (All data for these heavily poisoned $D_{2} O$ samples are 1 isted in Table $V$ and displayed in Figures $5,6,9$, and 10 .) The data points at $\Sigma_{a}=0.273 \mathrm{~cm}^{-1}$ were obtained only with a tailored incident spectrum closely matching the equilibrium distribution. This spectrum was supplied by heating the 4 -inch Slab Tank to $90^{\circ} \mathrm{C}$ and inserting between 


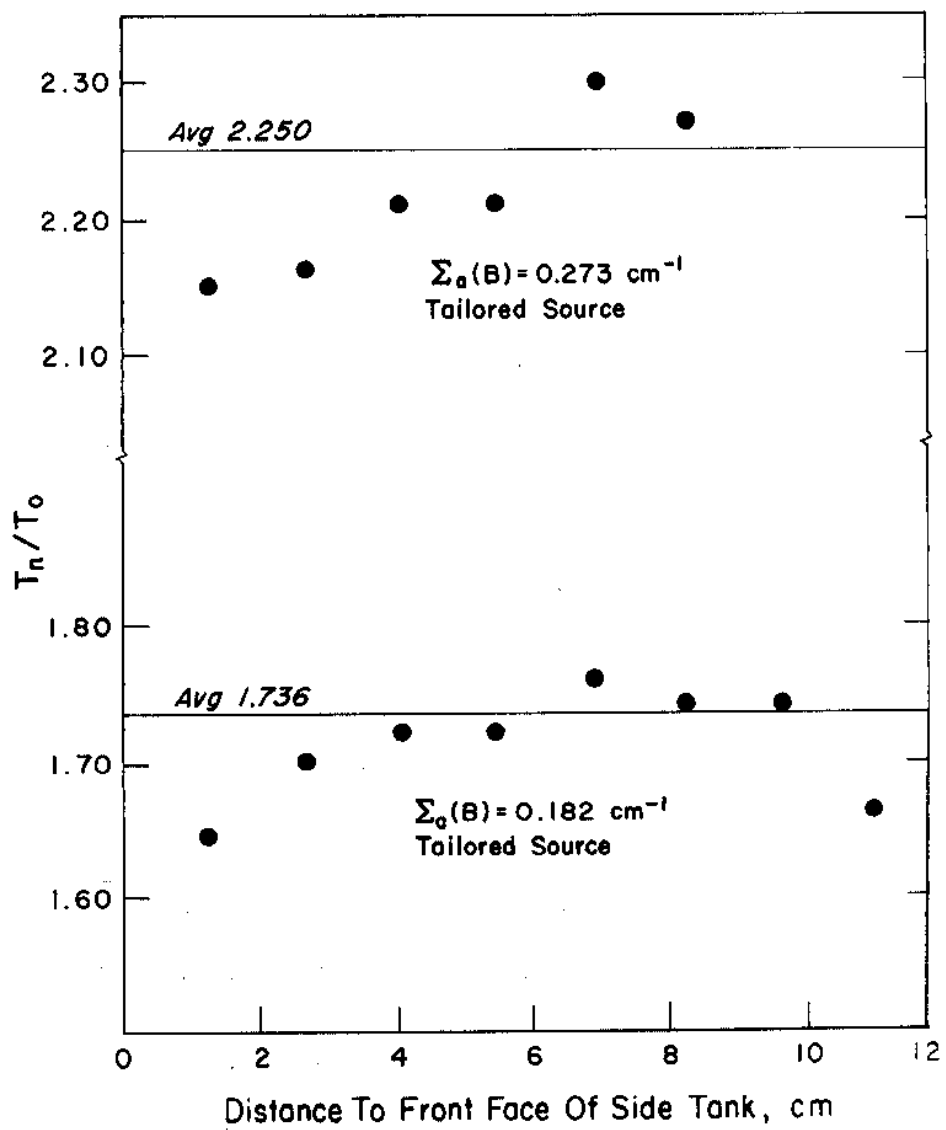

FIG. 10 NEUTRON TEMPERATURES DERIVED FROM SPECTRAL INDEX MEASUREMENTS IN HEAVILY POISONED $D_{2} O$ VERSUS DISTANCE INTO EXPONENTIAL FACILITY

the S1ab and Side Tanks sheets of boron-steel alloy that had a thermal neutron absorption thickness of 2.0 mean free paths (Figure 1). The spectral index measurements as a function of distance into the poisoned $\mathrm{D}_{2} \mathrm{O}$ (Figure 10 ) varied only slightly. Furthermore, the activation measurement at $\Sigma_{a}(B)=0.273 \mathrm{~cm}^{-1}$, shown at the top of Figure 5 , does not depart from simple exponential behavior over the entire experimental range.

The data points at the poison concentration around $\Sigma_{a}=$ $0.18 \mathrm{~cm}^{-1}$ were obtained with and without tailoring. At $\Sigma_{a}=$ $0.182 \mathrm{~cm}^{-1}$ the tailored spectrum was supplied by heating the 4-inch Slab Tank to $90^{\circ} \mathrm{C}$ and inserting a filter with a 1.0 mean free path thickness. Energy equilibrium again appeared to be established as seen in Figure 10. In contrast, at $\Sigma_{a}=0.180$ 
$\mathrm{cm}^{-1}$, where the incident spectrum from the SP was unaltered, energy equilibrium was never established within the experimental region, although the axial flux profile shown in Figure 5 seems to be exponential over half its range. THERMOS computations were also made for this case to correct the spectral measurements to the asymptotic case, but as seen in Figures 6 and 9 even this correction did not make the spectra agree completely with spectra obtained with the tailored source. Since this same correction technique was used for $\Sigma_{a}=0.121 \mathrm{~cm}^{-1}$ which was irradiated with an untailored source, we might expect this value of $T_{n(\infty)} / T_{0}$ to be too low.

As seen in Figure 6 , the measurements on $\mathrm{D}_{2} \mathrm{O}$ were not seemingly influenced by the $k=\left(\Sigma_{s}\right)_{\text {min }}$ limit. Corngold and Michael ${ }^{34}$ have commented about relaxation length measurements on beryllium which seemingly violate this same limit, except that the limit is here imposed at low energies by Bragg scattering. Analogous violations of similar theoretical limits have also been noted for pulsed measurements on crystalline moderators. Corngold and Durgun ${ }^{35}$ have recently given an interpretation of these measurements.

For the $D_{2} O$ static measurements, a simple qualitative explanation of the role of this limit may be given. The thermal neutron source feeding the assembly is a Maxwellian distribution. In any energy interval, the flux at that energy can fall off with distance no more rapidly than the rate at which neutrons are removed from this energy interval by capture or by scattering collisions to other energies. Thus, at very large distances from the source, the spatial variation of the measured activation profile must be detarmined by neutrons in the energy interval for which the removal cross section is a minimum, unless the energy average diffusion length for the Maxwellian distribution is long enough to exceed such "removal lengths" (inverse total macroscopic cross sections) at all energies. Since Maxwel1ian distributions formally extend to infinite energies, energies up to infinity should be included. It is necessary, however, to arbitrarily cut of the distribution at some finite energy to obtain meaningful results. The $k=\Sigma_{s}$ limit normally implies 
a cutoff in the ev to Kev range at energies where $\Sigma_{a}(1 / v)<<\Sigma_{s}$ = constant; even this range may be too high. (The cadmium shutter technique implies the source energy is cut off at $0.62 \mathrm{ev}$. The resultant limit is shown in Figure 6.) Perhaps a more meaningful (but still somewhat arbitrary) limit is one which includes all but a numerically negligible number of source neutrons. If we require that only one activation out of one thousand in a $1 / \mathrm{v}$ detector near the source is caused by higher energy neutrons, a cutoff energy of $8.7 \mathrm{kT}_{0}$ is obtained. At this energy, $\Sigma_{s}$ for $\mathrm{D}_{2} \mathrm{O}$ is slightly higher than the free atom value and the magnitude of the absorption cross section of the poisoned $\mathrm{D}_{2} \mathrm{O}$ is comparable. This limit is shown in Figure 6 and is seen to be consistent with the experimental values.

\section{REFERENCES}

1. N. P. Baumann. "Determination of Diffusion Coefficients for Thermal Neutrons in $\mathrm{D}_{2} \mathrm{O}$ at $20,100,165$, and $220^{\circ} \mathrm{C}$. "Nucl. Sci. and Eng. 14, 179 (1962).

2. H. C. Honeck and P. Michae1. "A Remark on the Measurement of the Diffusion Coefficient for Thermal Neutrons." Nucl. Sci. and Eng. 16, 140 (1963).

3. H. C. Honeck. On the Calculation of Thermal Neutron Diffusion Parameters. BNL-719 (C-32), Vol. IV, p. 1186, Brookhaven National Laboratory, Upton, N. Y. (1962).

4. J. W. Daughtry and A. W. Waltner. "Temperature Dependence of the Thermal Neutron Properties of $\mathrm{D}_{2} \mathrm{O} . "$ Trans. Am. Nucl. Soc. 7(2), $232(1964)$.

5. G. Kussmaul and H. Meister. "Thermal Neutron Diffusion Parameters of Heavy Water." Reactor Sci. and Technol. 17, 411 (1963).

6. B. K. Malaviya, I. Kaplan, D. O. Lanning, A. E. Profio, and T. J. Thompson. Studies of Reactivity and Related Parameters in Siightiy Enriched Uranium, Heavy Water Lattices. USAEC Report MITNE-49, Massachusetts Institute of Technology, Cambridge, Mass. (1964).

7. N. Corngold. "Some Transient Phenomena in ThermalizationTheory." Nucl. Sci. and Eng. 19, 80 (1964).

8. W. V. Baxter. A Monte carlo Code for the Transport of Neutrons. USAEC Report DP-446, E. I. du Pont de Nemours and Co., Savannah River Laboratory, Aiken, S. C. (1959). 
9. H. C. Honeck. THERMOS. A Thermalization Transport Theory Code for Reactor Lattice Calculations. USAEC Report BNL-5826, Brookhaven National Laboratory, Upton, N. Y. (1961).

10. E. Starr and J. Koppel. "Determination of Diffusion Hardening in Water." Nucl. Sci. and Eng. 14, 224 (1962).

11. E. Gon, L: Lidofsky, and H. Goldstein. "Pulsed-Source Measurements of Neutron-Diffusion Parameters in Water." Trans. Am. Nucl. Soc. 8(1), 274 (1965).

12. J. R. Stehn, M. D. Goldberg, B. A. Magurno, and R. Wiener-Chasman, Neutron Cross Sections. 2nd ed., Supplement No. 2, USAEC Report BNL-325, Brookhaven Nationa1 Laboratory, Upton, N. Y. (1964).

13. S. Glasstone and M. C. Edlund. The EZements of Nuclear Reactor Theory. p. 281, D. Van Nostrand Co. (1952).

14. N. G. Sjostrand. "On the Theory Underlying Diffusion Measurements with Pulsed Neutron Sources. Arkiv for Fysik Band 15, nr 12, 147 (1959).

15. A. Radkowsky. Temperature Dependence of Thermal Transport Mean Free Path from Experimental Data on Scattering Cross Section of Water. USAEC Report ANL-4476, Argonne National Laboratory, Lemont, I11. (1950).

16. R. C. Axtmann, L. A. Heinrich, R. C. Robinson, 0. A. Towler, and $\mathrm{J}$. W. Wade. Initial operation of the standard Pile. USAEC Report DP-32, E. I. du Pont de Nemours and Co., Savannah River Laboratory, Aiken, S. C. (1953).

17. L. C. Schmid and W. P. Stinson. Lutetium as a Spectral Index Detector. USAEC Report HW-66319, General Electric Co., Hanford Atomic Products Operation, Richland, Washington (1960).

18. W. M. Lopez and J. R. Beyster. "Measurement of Neutron Diffusion Parameters in Water by the Pulsed Neutron Method." Nucl. Sci. and Eng. 12, 190 (1962).

19. R. Peierls. "Statistical Error in Counting Experiments." Proc. Roy. Soc. (London) A149, 467 (1955).

20. J. I. Paulk and M. B. Stroud. "PEX Code." Private communication.

21. P. F. Nichols, E. G. Bilpuch, and H. W. Newson. "s- and p-Wave Neutron Spectroscopy, Part IV. Experimental Methods in the kev Region." Annals of Physics 8, 250 (1959).

22. N. P. Baumann and M. B. Stroud. "Self-Shielding of Detector Foils in Reactor Fluxes." Nucleonics 23(8), 98 (1965).

23. R. C. Kryter, G. P. Calame, R. R. Fullwood, and E. R. Gaerttner. "Measurement and Analysis of Time-Dependent Neutron Spectra in $\mathrm{D}_{2} \mathrm{O}$." Trans. Am. Nuc2. Soc. 8(1), 276 (1965). 
24. M. M. Bretscher and J. F. Meyer. "Diffusion Heating and Cooling of Thermal Neutrons in water." Proc. Indiana Acad. Sci. 73, 210 (1964).

25. H. P. Flatt and D. C. Baller. AIM-5, A Multigroup, oneDimensional Diffusion Equation Code. USAEC Report NAA-SR-4694, Atomics Int. Div., N. Am. Avia., Inc., Canoga Park, Calif. (1960).

26. A. K. Ghatak and H. C. Honeck. "Transient Spectra in Graphite." J. Nucl. Energy 19, 1 (1965).

27. E. Starr and G. A. Price. Measurement of the Diffusion Parameters of Graphite and Graphite-Bismuth by Pulsed Neutron Methods. USAEC Report BNL-719, (C32), Vol. III, p. 1034, Brookhaven National Laboratory, Upton, N. Y. (1962).

28. J. I. Paulk and A. W. Waltner. "The Diffusion Parameters of Heavy- and Light-Water Mixtures at Different Temperatures by pulsed-Neutron Methods." Trans. Am. Nucl. Soc. 5(2), 387 (1962).

29. H. D. Brown. Neutron Energy Spectra in Water. USAEC Report DP-64, E. I. du Pont de Nemours and Co., Savannah River Laboratory, Aiken, S. C. (1956).

30. K. Burkart. On the Hardening of Thermal Neutron spectra in Water and Boric Acid Solution. USAEC Report KFK 294, Gesellschaft fur Kernforschung, Karlsruhe (1965).

31. G. S. Stanford and K. E. Plumlee. "Linear Relationship Between Cadmium Ratio and Reactor Core Composition." Trans. Am. NuCl. Soc. B(1), 270 (1965).

32. C. H. Westcott. Effective Cross section Values for WellModerated Thermal Reactor Spectra. USAEC Report CRRP-960 (AECL-1101), Atomic Energy of Canada Ltd., Chalk River, Ont. (1960).

33. H. D. Brown and D. S. St. John. Neutron Energy Spectrum in $D_{0} O$. USAEC Report DP-33, E. I. du Pont de Nemours and Co., Săvannah River Laboratory, Aiken, S. C. (1954).

34. N. Corngold and P. Michael. "Some Transient Phenomena in Thermalization-Implications for Experiment." Nucl. Sci. and Eng. 19, 91 (1964).

35. N. Corngold and K. Durgun. "The Decay Constant of a Neutron Pulse." Nucl. Sci. and Eng. 25, 450 (1966). 


\section{APPENDIX}

CORRECTIONS TO PULSED MEASUREMENTS IN $\mathrm{D}_{2} \mathrm{O}$

1. Fix

$$
\delta_{z}\left(D_{2} 0\right)=0.7104 \lambda_{t r}=1.79 \mathrm{~cm} \text { at } 29^{\circ} \mathrm{C}^{1}
$$

2. Compute aluminum reflector savings for side, top, and bottom:

$$
\delta(A 1)=d(A 1) \Sigma(A 1)^{\operatorname{tr}} / \Sigma\left(D_{2} 0\right)^{\operatorname{tr}}=0.212 \mathrm{~d}(\mathrm{~A} 1)
$$

3. Compute extrapolation distance for curved surface of radius $R$ :

$$
\delta_{r}\left(D_{2} O\right)=\delta_{z}\left(D_{2} O\right)\left[\frac{1}{1.0+0.5\left[\delta_{z}\left(D_{2} O\right) / R\right]}\right]
$$

4. Compute $\mathrm{B}^{2}$ including aluminum:

$$
\begin{aligned}
B^{2}=B_{r}^{2}+B_{z}^{2}= & {\left[\frac{2.405}{R+\delta_{r}\left(D_{2} 0\right)+\delta_{s}(A 1)}\right]^{2} } \\
& +\left[\frac{3.1416}{H+2 \delta_{z}\left(D_{2} O\right)+\delta_{t}(A 1)+\delta_{b}(A 1)}\right]^{2}
\end{aligned}
$$

where $\mathrm{H}$ is the moderator height.

5. Divide $\left(\lambda-\lambda_{0}\right)_{T_{m}}$ by $B^{2}$, where $T_{m}$ is the moderator temperature:

$$
\frac{\left(\lambda-\lambda_{o}\right)^{T} T_{m}}{B^{2}}=(v D) e_{\text {eff }}^{T_{m}} \cong v^{T_{m}} D_{\text {eff }}^{{ }^{T}}
$$


6. Correct for minor deviations of $\mathrm{T}_{\mathrm{m}}$ from pulsed reference moderator temperature of $29^{\circ} \mathrm{C}\left(302^{\circ} \mathrm{K}\right)$. The relevant exact equations are:

$$
\begin{gathered}
\mathrm{D}_{\text {eff }}^{29^{\circ} \mathrm{C}}=\mathrm{D}_{\text {eff }}^{\mathrm{T}}\left[0.69+0.31\left(\frac{\mathrm{T}_{\mathrm{m}}}{293}\right)^{\frac{1}{2}}\right]^{-1}\left[0.69+0.31\left(\frac{302}{293}\right)^{\frac{1}{2}}\right] \\
\mathrm{v}^{29^{\circ} \mathrm{C}}=\mathrm{v}^{\mathrm{T}} \mathrm{m}\left(\frac{302}{\mathrm{~T}_{\mathrm{m}}}\right)^{\frac{3}{2}}
\end{gathered}
$$

These relations give, for small differences $\Delta \mathrm{T}$ from $29^{\circ} \mathrm{C}$, a fractional change in (VD) of

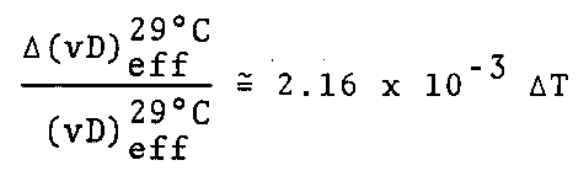

7. Compute $\left[\frac{\lambda-\lambda_{o}}{B^{2}}\right]_{29^{\circ} \mathrm{C}}=(v D){ }_{\text {eff }}^{\mathrm{T}}-\Delta(v D)=(v D) \underset{\text { eff }}{29^{\circ} \mathrm{C}}$

8. Plot $(v D))_{\text {eff }}^{29^{\circ} \mathrm{C}}$ and estimate $(v D){ }_{0}^{29^{\circ} \mathrm{C}}$ at $B^{2}=0$.

9. $\frac{(v D)_{e f f}^{29^{\circ} \mathrm{C}}}{(v D)_{\mathrm{O}}^{29^{\circ} \mathrm{C}}}=\frac{\left(\frac{\mathrm{T}_{\mathrm{n}}}{302}\right)^{\frac{1}{2}}\left[0.69+0.31\left(\frac{\mathrm{T}_{\mathrm{n}}}{293}\right)^{\frac{1}{2}}\right]}{\left[0.69+0.31\left(\frac{302}{293}\right)^{\frac{1}{2}}\right]}$ where ${ }_{i}{ }_{\mathrm{n}}$ is the neutron

The ratio on the left is given by the experiment; thus $\mathrm{T}_{\mathrm{n}}$ may be solved graphically from the data to evaluate $\mathrm{D}_{\mathrm{n}}$ from the equation of Step 6 if $T_{m}$ is replaced by $T_{n}$.

10. Compute new slab type extrapolation distance:

$$
\delta_{z}\left(D_{2} 0\right)=0.7104 \lambda_{\text {eff }}^{\operatorname{tr}}=2.13 \mathrm{D}_{\text {eff }}^{\mathrm{T}}
$$

11. Go back to Step 3 and iterate Steps 3 through 10 until convergence is obtained in (vD) $29^{\circ} \mathrm{C}$. (Step 2 can be left out of iteration since $\delta_{A 1}$ is quite sma11.) 